\title{
1.9-million- and 2.4-million-year-old artifacts and stone tool-cutmarked bones from Ain Boucherit, Algeria
}

\author{
Mohamed Sahnouni ${ }^{1,2,3 *}$, Josep M. Parés ${ }^{1}$, Mathieu Duval ${ }^{4,1}$, Isabel Cáceres ${ }^{5,6}$, Zoheir Harichane ${ }^{2,7}$,

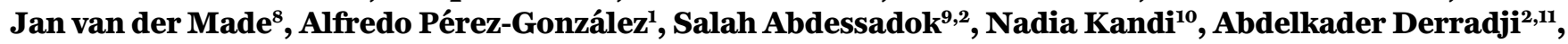 \\ Mohamed Medig"1, Kamel Boulaghraif ${ }^{2,12}$, Sileshi Semaw ${ }^{1,3}$
}

${ }^{1}$ Centro Nacional de Investigación sobre la Evolución Humana (CENIEH), Burgos, Spain. ${ }^{2}$ Centre National de Recherches Préhistoriques, Anthropologiques et Historiques (CNRPAH), Algiers, Algeria. ${ }^{3}$ Stone Age Institute and Anthropology Department, Indiana University, Bloomington, IN, USA. ${ }^{4}$ Australian Research Centre for Human Evolution, Griffith University, Brisbane, Queensland, Australia. ${ }^{5}$ Àrea de Prehistòria, Universitat Rovira i Virgili, Tarragona, Spain. ${ }^{6}$ Institut Català de Paleoecologia Humana i Evolució Social (IPHES), Tarragona, Spain. ${ }^{7}$ Musée National du Bardo, Algiers, Algeria. ${ }^{8}$ Museo Nacional de Ciencias Naturales and Consejo Superior de Investigaciones Científicas (CSIC), Madrid, Spain. 'Département Homme et Environnement, Museum National d'Histoire Naturelle (MNHN), Paris, France. ${ }^{10}$ Département d'Archéologie, Université Lamine Debaghine Sétif 2, Sétif, Algeria. ${ }^{11}$ Institut d'Archéologie, Université Alger 2, Algiers, Algeria. ${ }^{12}$ Dipartimento di Studi Umanistici, Università Degli Studi di Ferrara, Ferrara, Italy.

*Corresponding author. Email: mohamed.sahnouni@cenieh.es

East Africa has provided the earliest known evidence for Oldowan stone artifacts and hominin induced stone tool cutmarks dated to $\sim 2.6$ million years ago (Ma). The $\sim 1.8 \mathrm{Ma}$ stone artifacts from Ain Hanech (Algeria) were considered to represent the oldest archaeological materials in North Africa. Here we report older stone artifacts and cutmarked bones excavated from two nearby deposits at Ain Boucherit estimated to $\sim 1.9 \mathrm{Ma}$, and the older to $\sim 2.4 \mathrm{Ma}$. Hence, the Ain Boucherit evidence shows that ancestral hominins inhabited the Mediterranean fringe in Northern Africa much earlier than previously thought. The evidence strongly argues for early dispersal of stone tool manufacture and use from East Africa, or a possible multiple origin scenario of stone technology in both East and North Africa.

The earliest archaeological evidence for the Oldowan and associated fossil bones with evidence of butchery is within the 2.6-1.9 Ma time interval, primarily from East Africa (1-7). Most paleoanthropologists believe that early hominins dispersed into Northern Africa much later (8). Continued research at Ain Hanech and El Kherba (Algeria) over the past two decades has expanded the geographic range and pushed back the evidence for hominin stone tool use and carnivory to $\sim 1.8 \mathrm{Ma}(9-11)$. We recently explored the nearby deposits at Ain Boucherit (Algeria) and report evidence of Oldowan stone tools and associated hominin-modified fossil bones from two distinct strata estimated to $\sim 2.4$ and $\sim 1.9 \mathrm{Ma}$, respectively.

Ain Boucherit is an archaeological locality in the Ain Hanech research area in northeastern Algeria. The research area is in the Beni Fouda basin, one of the several intramontane sedimentary basins in the High Plateaus of eastern Algeria. The stone tools and associated fossil bones at Ain Boucherit come from two distinct strata situated in a sedimentary outcrop cut by a deep ravine. The archeological strata belong to the Ain Hanech Formation (Fm), which rests on an erosive disconformity atop the Oued Laatach Fm [supplementary text S2, see (12)]. The Ain Hanech Fm contains six stratigraphic members $(\mathrm{Mb})$, bottom to top, from $\mathrm{P}$ to $\mathrm{U}$ (Fig. 1), consisting of fluvial deposits made of alternating gravels and sandstone with mudstone. The lowermost artifact-bearing stratum (AB-Lw) is located in the sequence near the top of $\mathrm{Mb} \mathrm{P}$. Within this stratum, presence of fossil fauna was known $(13,14)$, and we excavated in situ Oldowan artifacts in association with a sizable faunal assemblage, some with evidence of stone tool cutmarks. The lithic artifacts were overall fresh, but the bones were subjected to minor alterations (fig. S4). The materials were sealed in fine-grained sediments consisting primarily of silt, fine sand, and clay (fig. S6).

The second artifact-bearing stratum (AB-Up), $9 \mathrm{~m}$ higher in the sequence, is sealed by the overlying $3.5 \mathrm{~m}$ thick $\mathrm{Mb} \mathrm{R}$ deposits. A $38 \mathrm{~m}^{2}$ excavation yielded a faunal assemblage associated with Oldowan artifacts encased in a $0.40 \mathrm{~m}$ thick silty clay and fine sand, underlain by gravels. The finegrained sediment context (fig. S6), the fresh quality of the artifacts with a large amount of debitage, and the absence of preferred orientation or high dip of the remains suggest a low energy depositional environment (figs. S12 and S13). Microscopic observations show some taphonomic alterations related to water activities but sorting of skeletal parts is entirely absent (fig. S4).

The age of the Aïn Boucherit archaeological materials is constrained by means of magnetostratigraphy, Electron Spin Resonance (ESR), and mammalian biochronology. The magnetostratigraphic study was carried out on two sections, totaling $50 \mathrm{~m}$ thick profile (Fig. 1) [materials and methods 1 , see (12)]. The results indicate a vertical succession of both normal 
and reversed magnetozones. The independent age control provided by numerical dating (ESR method) enabled us to anchor the local magnetic polarity stratigraphy to the Global Polarity Time Scale (GPTS) (15). ESR dating was performed on optically bleached quartz grains from $\mathrm{Mb}$ P, located $\sim 1 \mathrm{~m}$ below AB-Lw (Fig. 1). The ESR age calculations, using the Multiple Centers approach (16), yielded highly consistent dates for the $\mathrm{Al}$ and Ti-Li centers. A final combined Al-Ti age is $1.92 \pm 0.18 \mathrm{Ma}(1 \sigma)$ (fig. S3 and table S4). Although the uncertainty associated with the dose rate evaluation may impact this result [materials and methods 2, see (12)], this numerical chronology unambiguously indicates that the reverse magnetozone in the lower part of the Ain Hanech Formation corresponds to the early Matuyama chron (C2r), which is chronologically constrained between 1.94-2.58 Ma. Subsequent magnetostratigraphic interpretations indicate that the bottom of the sequence begins with the Gilbert reversed polarity (C2Ar), followed by the Gauss (C2An) normal polarity, ending with the Matuyama above the Olduvai subchron (C2n). Level AB-Lw in Mb P falls within the lower Matuyama reversed chron (C2r), while level $\mathrm{AB}-\mathrm{Up}$ in $\mathrm{Mb}$ R correlates to the bottom of $\mathrm{C} 2 \mathrm{n}$ (9). The Aïn Hanech and El-Kherba artifact-bearing layers, located higher up in $\mathrm{Mb} \mathrm{T}$, are near the top of Olduvai, thus dating to $\sim 1.78 \mathrm{Ma}(9)$. The calcrete deposits in Member U, which preserve Acheulean artifacts, are in the reverse chron C1r postdating Olduvai.

This chronostratigraphic framework is supported by mammalian taxa (table S8), several of which are of biochronological relevance. Kolpochoerus heseloni $(=$ K. limnetes) (17) is present at Ain Hanech (fig. S7) and El Kherba (18) and its last appearance is $\sim 1.7 \mathrm{Ma}(19,20)$. Anancus is present at ABLw (Mb P) (fig. S7, 1a and 1b) and at Ain Hanech (13), with the youngest occurrence in East, South, and North Africa, and Europe, dating to around 3.8-3.5, <3.1, 2.5, and 2.3-2.2 Ma, respectively $(21,22)$. In the Indian Subcontinent at Pinjor, and in China in the Nihewan Fm $(23,24)$, the latest record for Anancus dates to the earliest Pleistocene. Equus numidicus from AB-Lw and the smaller E. tabeti from Ain Hanech and El Kherba have extremely gracile metapodials, while

African species younger than $\sim 1.2 \mathrm{Ma}$ are more robust (fig. S8), i. e. until the appearance of the Late Pleistocene $E$. melkiensis [supplementary text S4, see (12)]. These taxa support an early post-Olduvai age for Ain Hanech and El Kherba $(\sim 1.8 \mathrm{Ma})(9)$, and the correlation of $\mathrm{AB}-\mathrm{Up}$ and $\mathrm{AB}-\mathrm{Lw}$ to Olduvai and early Matuayama (C2r.2r) subchrons, respectively.

Therefore, the magnetostratigraphic and biochronological data combined with the ESR age lead to the following interpretations: (i) AB-Lw is chronostratigraphically positioned between the beginning of the Olduvai subchron and the top of the Gauss chron and thus, it is chronologically constrained between 1.94-2.58 Ma; and (ii) AB-Up has been deposited during the Olduvai subchron and has therefore an age between 1.94-1.78 Ma. Thus, the age of the Olduvai and the Gauss chrons (15), and sediment accumulation rates allowed further age estimation [supplementary text $\mathrm{S} 1$, see (12)], which could not be achieved with the ESR result alone due to current limitations of the method for long chronologies. Assuming constant rates during the Olduvai and the Matuyama C2r and neglecting compaction effects, we estimate the age of $\mathrm{AB}-\mathrm{Up}$ and $\mathrm{AB}-\mathrm{Lw}$ to $1.92 \pm 0.05 \mathrm{Ma}$ and $2.44 \pm 0.14 \mathrm{Ma}$, respectively (Fig. 2). The latter is, in our opinion, the most reasonable age estimate for AB-Lw, although we do acknowledge a slightly younger age given the possibility of uncertainty on the position of the Gauss-Matuyama boundary [supplementary text S1, see (12)].

The lithic assemblages from $\mathrm{AB}-\mathrm{Lw}$ and $\mathrm{AB}-\mathrm{Up}$ are made on limestone and flint, and consist of 17 and 236 specimens, respectively (Fig. 3, fig. S11, and table S10). The probable sources of the limestone and flint raw materials were the nearby channel beds [supplementary text S5, see (12); fig. S10]. The technological and typological features of the Ain Boucherit stone assemblages are similar to the Oldowan from the Early Pleistocene sites in East Africa. The artifact assemblage from $\mathrm{AB}-\mathrm{Lw}$ includes 7 cores, 9 flakes, and one retouched piece (Fig. 3). The AB-Lw cores are variably flaked with most retaining residual cortical areas, ranging from lightly flaked with 2-8 scars to heavily flaked with one specimen bearing 29 scars. Despite marked technological similarities, some of the cores are predominantly polyhedral/subspherical. The flakes range between $30-58 \mathrm{~mm}$ in length, and most retain cortex. The retouched specimen is a notched scraper on a cortical flake made of flint.

Abundant stone artifacts were recovered from AB-Up: 121 cores, 65 whole flakes $(>2 \mathrm{~cm}), 3$ retouched flakes, and 47 fragments (Fig. 3). The cores are primarily made on limestone (95.8\%) with a few made on flint (4.13\%). The cores include unifacial choppers (16.94\%), bifacial choppers (8.05\%), polyhedrons (23.05\%), subspheroids (1.69\%), and spheroids $(0.84 \%)$. They were variably flaked, from light to heavy; over half still retain cortex. Specimens with high scar counts (1530 ) represent $11.5 \%$ of the assemblage. There are also facetted subspheroids with pitting marks suggestive of possible pounding activities. The flakes are predominantly made on limestone, and nearly half of the specimens retain cortex on dorsal faces and platforms. The retouched pieces, chiefly in flint, are small and can be typologically characterized as scrapers and notched scrapers.

The faunal assemblages of AB-Lw and AB-Up include 296 $(\mathrm{MNI}=19)$ and $277(\mathrm{MNI}=14)$ fossil bones, respectively. They are primarily composed of small and medium-sized bovids and equids (tables S5 to S7), also with the best skeletal representations; the appendicular parts in both levels being the 
most abundant, followed by cranial and axial elements. Evidence of cutmarked and hammerstone-percussed bones is present in both assemblages (Fig. 4). The cutmarks are characterized by isolated or grouped striae with straight trajectory and oblique or transversal orientations. Although variable in depth, many of the specimens have narrow $\mathrm{V}$-shaped cutmarks in cross-section with clear internal micro striation and Hertzian cones. In AB-Lw, cutmarks are recognized on 17 bones (5.7\% of the assemblage), half of which belong to very small or small-sized animals. The cutmarks are located primarily on limb bones, on ribs, and on cranial remains, suggesting skinning, evisceration, and defleshing activities (25) (table S7). Four of the bones show hominin induced percussion marks, including percussion pits, medullary or cortical percussion notches, and a bone flake, implying marrow extraction. The AB-Up bone assemblage yielded 2 cutmarked bones (an equid tibia and a medium-sized long bone) and 7 hammerstone-percussed long bones, which include large (equid) and medium-sized animals and a tibia of small-sized animal.

The Ain Boucherit stone assemblages are typical of the Oldowan technology, though with subtle typological variations compared to the near contemporary East African assemblages dated to 2.6-1.9 Ma, such as Gona, Omo, Hadar (Ethiopia), West-Turkana, and Kanjera (Kenya) (1, 3-6). In addition to the ubiquitous Mode I core/flake stone assemblages, Ain Boucherit also yielded facetted subspheroids/spheroids. In East Africa variable Mode I artifact assemblages are documented with the early Oldowan (2.6-2.0 Ma), but facetted spheroids are unknown at these early sites. The observed variability between East and North Africa may be a result of differences in the type and qualities of raw materials used or to function-related factors that we have yet to identify. Moreover, except for Gona and Kanjera, Ain Boucherit stands alone in Africa as the only site with evidence of cutmarked and hammerstone-percussed bones associated with in situ stone tools dated to 2.4 Ma. In addition to Kanjera, the Ain Boucherit materials represent a larger sample excavated from a single site allowing to make stronger inferences on how hominins butchered carcasses. The Ain Boucherit data unambiguously shows hominin exploitation of meat and marrow from all animal size categories and skeletal parts involving skinning, evisceration, and defleshing of upper and intermediate limbs. These activities suggest early access to animal carcasses by hominins $(25,26)$.

For decades, East Africa has been considered the place of origin of the earliest hominins and lithic technology. Surprisingly, the earliest currently known hominin dated to $7.0 \mathrm{Ma}$, and the $\sim 3.3 \mathrm{Ma}$ Australopithecus bahrelghazali have been discovered in Chad, located in the Sahara thousands of $\mathrm{km}$ away from the East African Rift $(27,28)$. Now that Ain Boucherit has yielded Oldowan archaeology estimated to 2.4
Ma, Northern Africa and the Sahara may be a repository of further archaeological materials. Despite its distance from East Africa, the evidence from Ain Boucherit implies either rapid expansion of stone tool manufacture from East Africa to other parts of the continent, or possible multiple origin scenario of ancestral hominins and stone technology in both East and North Africa. Based on the potential of Ain Boucherit and the adjacent sedimentary basins, we suggest that hominin fossils and Oldowan artifacts as old as those documented in East Africa could be discovered in North Africa as well.

\section{REFERENCES AND NOTES}

1. S. Semaw, The world's oldest stone artefacts from Gona, Ethiopia: Their implications for understanding stone technology and patterns of human evolution between 2.6-1.5 million years ago. J. Archaeol. Sci. 27, 1197-1214 (2000). doi:10.1006/jasc.1999.0592

2. S. Semaw, M. J. Rogers, J. Quade, P. R. Renne, R. F. Butler, M. Dominguez-Rodrigo, D. Stout, W. S. Hart, T. Pickering, S. W. Simpson, 2.6-Million-year-old stone tools and associated bones from OGS-6 and OGS-7, Gona, Afar, Ethiopia. J. Hum. Evol. 45, 169-177 (2003). doi:10.1016/S0047-2484(03)00093-9 Medline

3. H. Roche, A. Delagnes, J.-P. Brugal, C. Feibel, M. Kibunjia, V. Mourre, P.-J. Texier, Early hominid stone tool production and technical skill 2.34 Myr ago in West Turkana, Kenya. Nature 399, 57-60 (1999). doi:10.1038/19959 Medline

4. A. Delagnes, J.-R. Boisserie, Y. Beyene, K. Chuniaud, C. Guillemot, M. Schuster, Archaeological investigations in the Lower Omo Valley (Shungura Formation, Ethiopia): New data and perspectives. J. Hum. Evol. 61, 215-222 (2011) doi:10.1016/j.jhevol.2011.03.008 Medline

5. W. H. Kimbel, R. C. Walter, D. C. Johanson, K. E. Reed, J. L. Aronson, Z. Assefa, C. W. Marean, G. G. Eck, R. Bobe, E. Hovers, Y. Rak, C. Vondra, T. Yemane, D. York, Y. Chen, N. M. Evensen, P. E. Smith, Late Pliocene Homo and Oldowan Tools from the Hadar Formation (Kada Hadar Member), Ethiopia. J. Hum. Evol. 31, 549-561 (1996). doi:10.1006/jhev.1996.0079

6. T. Plummer, L. C. Bishop, P. Ditchfield, J. Hicks, Research on late Pliocene Oldowan sites at Kanjera South, Kenya. J. Hum. Evol. 36, 151-170 (1999). doi:10.1006/jhev.1998.0256 Medline

7. J. V. Ferraro, T. W. Plummer, B. L. Pobiner, J. S. Oliver, L. C. Bishop, D. R. Braun, P. W. Ditchfield, J. W. Seaman 3rd, K. M. Binetti, J. W. Seaman Jr., F. Hertel, R. Potts, Earliest archaeological evidence of persistent hominin carnivory. PLOS ONE 8, e62174 (2013). doi:10.1371/journal.pone.0062174 Medline

8. R. Klein, The Human Career (Univ. of Chicago Press, ed. 3, 2009).

9. J. M. Parés, M. Sahnouni, J. Van der Made, A. Pérez-González, Z. Harichane, A. Derradji, M. Medig, Early human settlements in Northern Africa: Paleomagnetic evidence from the Ain Hanech Formation (northeastern Algeria). Quat. Sci. Rev. 99, 203-209 (2014). doi:10.1016/i.quascirev.2014.06.020

10. M. Sahnouni, D. Hadjouis, J. van der Made, Ael.-K. Derradji, A. Canals, M. Medig, H. Belahrech, Z. Harichane, M. Rabhi, Further research at the Oldowan site of Ain Hanech, north-eastern Algeria. J. Hum. Evol. 43, 925-937 (2002). doi:10.1006/jhev.2002.0608 Medline

11. M. Sahnouni, J. Rosell, J. van der Made, J. M. Vergès, A. Ollé, N. Kandi, Z. Harichane, A. Derradji, M. Medig, The first evidence of cut marks and usewear traces from the Plio-Pleistocene locality of El-Kherba (Ain Hanech), Algeria: Implications for early hominin subsistence activities circa 1.8 Ma. J. Hum. Evol. 64, 137-150 (2013). doi:10.1016/j.jhevol.2012.10.007 Medline

12. Materials and methods 1 to 3 and supplementary text $\mathrm{S} 1$ to $\mathrm{S} 5$ are provided as supplementary materials.

13. C. Arambourg, Les Vertébrés du Pléistocène de l'Afrique du Nord, Volume 1 (Archives du Muséum national d'histoire naturelle Series, vol. 10, Kapp \& Lahure, Paris, 1970), pp. 1-127.

14. C. Arambourg, Les Vertébrés villafranchiens d'Afrique du Nord (Singer-Polignac, 1979).

15. F. M. Gradstein, J. G. Ogg, M. D. Schmitz, G. M. Ogg, Eds., The Geologic Time Scale (Elsevier, ed. 1, 2012).

16. S. Toyoda, P. Voinchet, C. Falguères, J. M. Dolo, M. Laurent, Bleaching of ESR 
signals by the sunlight: A laboratory experiment for establishing the ESR dating of sediments. Appl. Radiat. Isot. 52, 1357-1362 (2000). doi:10.1016/S09698043(00)00095-6 Medline

17. H. S. B. Cooke, The status of the African fossil suids Kolpochoerus limnetes (Hopwood, 1926), K. phacochoeroides (Thomas, 1884) and "K." afarensis (Cooke, 1978). Geobios 30, 121-126 (1997). doi:10.1016/S0016-6995(97)80262-8

18. M. Sahnouni, J. van der Made, "The Oldowan in North Africa within a biochronological framework," in The Cutting Edge: New Approaches to the Archaeology of Human Origins, K. Schick, N. Toth, Eds. (Stone Age Institute Press, 2009), pp. 179-210.

19. T. D. White, "African omnivores: Global climatic change and Plio-Pleistocene hominids and suids," in Paleoclimate and Evolution, With Emphasis on Human Origins, E. S. Vrba, G. H. Denton, T. C. Partridge, L. H. Burckle, Eds. (Yale Univ. Press, 1995), pp. 369-384.

20. H. S. B. Cooke, "Stratigraphic variation in Suidae from the Shungura Formation and some coeval deposits," in Hominin Environments in the East African Pliocene: An Assessment of the Faunal Evidence, R. Bobe, Z. Alemseged, A. K. Behrensmeyer, Eds. (Springer, 2007), pp. 107-127.

21. W. J. E. Sanders, E. Gheerbrant, J. M. Harris, H. Saegusa, C. Delmer, "Proboscidea," in Cenozoic Mammals of Africa, L. Werdelin, W. J. Sanders, Eds. (Univ. California Press, Berkeley, 2010), pp. 161-251.

22. G. Garrido, G. A. Arribas, The last Iberian gomphothere (Mammalia, Proboscidea): Anancus arvernensis mencalensis nov. ssp. from the earliest Pleistocene of the Guadix Basin (Granada, Spain). Palaeontol. Electronica 17, 1-16 (2014).

23. A. C. Nanda, Comments on the Pinjor mammalian fauna of the Siwalik Group in relation to the post-Siwalik faunas of Peninsular India and Indo-Gangetic Plain. Quat. Int. 192, 6-13 (2008). doi:10.1016/j.quaint.2007.06.022

24. G.-F. Chen, The genus Anancus Aymard, 1855 (Proboscidea, Mammalia) from the Late Neogene of northern China. Vertebrata PalAsiatica 37, 175-189 (1999).

25. P. J. Nilssen, "An actualistic butchery study in South Africa and its implications for reconstructing hominid strategies of carcass acquisition and butchery in the Upper Pleistocene and Plio-Pleistocene," thesis, University of Cape Town, South Africa (2000).

26. M. Domínguez-Rodrigo, T. R. Pickering, S. Semaw, M. J. Rogers, Cutmarked bones from Pliocene archaeological sites at Gona, Afar, Ethiopia: Implications for the function of the world's oldest stone tools. J. Hum. Evol. 48, 109-121 (2005). doi:10.1016/j.jhevol.2004.09.004 Medline

27. M. Brunet, A. Beauvilain, Y. Coppens, E. Heintz, A. H. E. Moutaye, D. Pilbeam, The first australopithecine 2,500 kilometres west of the Rift Valley (Chad). Nature 378, 273-275 (1995). doi:10.1038/378273a0 Medline

28. M. Brunet, F. Guy, D. Pilbeam, H. T. Mackaye, A. Likius, D. Ahounta, A. Beauvilain, C. Blondel, H. Bocherens, J.-R. Boisserie, L. De Bonis, Y. Coppens, J. Dejax, C. Denys, P. Duringer, V. Eisenmann, G. Fanone, P. Fronty, D. Geraads, T. Lehmann, F. Lihoreau, A. Louchart, A. Mahamat, G. Merceron, G. Mouchelin, O. Otero, P. Pelaez Campomanes, M. Ponce De Leon, J.-C. Rage, M. Sapanet, M. Schuster, J. Sudre, P. Tassy, X. Valentin, P. Vignaud, L. Viriot, A. Zazzo, C. Zollikofer, A new hominid from the Upper Miocene of Chad, Central Africa. Nature 418, 145-151 (2002). doi:10.1038/nature00879 Medline

29. M. Sahnouni, J. de Heinzelin, The site of Ain Hanech revisited: New investigations at this Lower Pleistocene site in northern Algeria. J. Archaeol. Sci. 25, 1083-1101 (1998). doi:10.1006/jasc.1998.0278

30. J. L. Kirschvink, The least squares lines and plane analysis of paleomagnetic data. Geophys. J. R. Astron. Soc. 62, 699-718 (1980). doi:10.1111/j.1365246X.1980.tb02601.X

31. J. D. A. Zijderveld, "A.C. demagnetization of rocks: analysis of results," in Methods in Palaeomagnetism, D. W. Collinson, K. M. Creer, S. K. Runcorn, Eds. (Elsevier, 1967), pp. 254-286.

32. M. Duval, L. J. Arnold, V. Guilarte, M. Demuro, M. Santonja, A. Pérez-González, Electron spin resonance dating of optically bleached quartz grains from the Middle Palaeolithic site of Cuesta de la Bajada (Spain) using the multiple centres $\begin{array}{llll}\text { approach. Quat. Geochronol. 37, 82-96 (2017). } & \end{array}$ doi:10.1016/i.quageo.2016.09.006

33. M. Duval, V. Guilarte Moreno, Assessing the influence of the cavity temperature on the ESR signal of the Aluminum center in quartz grains extracted from sediment. Anc. TL 30, 11-16 (2012).

34. S. Toyoda, C. Falguères, The method to represent the ESR signal intensity of the aluminium hole center in quartz for the purpose of dating. Advances in ESR Applications 20, 7-10 (2003).

35. M. Duval, V. Guilarte, ESR dosimetry of optically bleached quartz grains extracted from Plio-Quaternary sediment: Evaluating some key aspects of the ESR signals associated to the Ti-centers. Radiat. Meas. 78, 28-41 (2015). doi:10.1016/j.radmeas.2014.10.002

36. S. L. Forman, J. Pierson, K. Lepper, "Luminescence geochronology," in Quaternary Geochronology: Methods and Applications, J. S. Noller, J. M. Sowers, W. R. Lettis, Eds. (American Geophysical Union, Washington, DC, 2000), pp. 157-176.

37. M. Duval, L. J. Arnold, Field gamma dose-rate assessment in natural sedimentary contexts using $\mathrm{LaBr}_{3}(\mathrm{Ce})$ and $\mathrm{Nal}(\mathrm{TI})$ probes: A comparison between the "threshold" and "windows" techniques. Appl. Radiat. Isot. 74, 36-45 (2013). doi:10.1016/j.apradiso.2012.12.006 Medline

38. G. Guérin, N. Mercier, G. Adamiec, Dose-rate conversion factors: Update. Anc. TL 29, 5-8 (2011).

39. D. Vandenberghe, F. De Corte, J. P. Buylaert, J. Kučera, P. Van den Haute, On the internal radioactivity in quartz. Radiat. Meas. 43, 771-775 (2008). doi:10.1016/j.radmeas.2008.01.016

40. B. J. Brennan, R. G. Lyons, S. W. Phillips, Attenuation of alpha particle track dose for spherical grains. Nucl. Tracks Radiat. Meas. 18, 249-253 (1991). doi:10.1016/1359-0189(91)90119-3

41. B. J. Brennan, Beta doses to spherical grains. Radiat. Meas. 37, 299-303 (2003). doi:10.1016/S1350-4487(03)00011-8

42. R. Grün, A cautionary note: Use of 'water content' and 'depth for cosmic ray dose rate' in AGE and DATA programs. Anc. TL 12, 50-51 (1994).

43. J. R. Prescott, J. T. Hutton, Cosmic ray and gamma ray dosimetry for $T L$ and $E S R$. Nucl. Tracks Radiat. Meas. 14, 223-227 (1988). doi:10.1016/13590189(88)90069-6

44. J. R. Prescott, J. T. Hutton, Cosmic ray contributions to dose rates for luminescence and ESR dating: Large depths and long-term time variations. Radiat. Meas. 23, 497-500 (1994). doi:10.1016/1350-4487(94)90086-8

45. K. Beerten, J. Lomax, K. Clémer, A. Stesmans, U. Radtke, On the use of Ti centres for estimating burial ages of Pleistocene sedimentary quartz: Multiple-grain data from Australia. Quat. Geoch. 1, 151-158 (2006). doi:10.1016/j.quageo.2006.05.037

46. K. Beerten, A. Stesmans, The use of Ti centers for estimating burial doses of single quartz grains: A case study from an aeolian deposit $\sim 2$ Ma old. Radiat. Meas. 41, 418-424 (2006). doi:10.1016/j.radmeas.2005.10.004

47. H. T. Bunn, J. W. K. Harris, G. Isaac, Z. Kaufulu, E. Kroll, K. Schick, N. Toth, A. K. Behrensmeyer, FxJj50: An early Pleistocene site in northern Kenya. World Archaeol. 12, 109-136 (1980). doi:10.1080/00438243.1980.9979787

48. H. T. Bunn, Patterns of skeletal representation and hominid subsistence activities at Olduvai Gorge, Tanzania, and Koobi Fora, Kenya. J. Hum. Evol. 15, 673-690 (1986). doi:10.1016/S0047-2484(86)80004-5

49. R. J. Blumenschine, C. W. Marean, S. D. Capaldo, Blind tests of inter-analyst correspondence and accuracy in the identification of cut marks, percussion marks, and carnivore tooth marks on bone surfaces. J. Archaeol. Sci. 23, 493-507 (1996). doi:10.1006/jasc.1996.0047

50.R. L. Lyman, Quantitative Paleozoology (Cambridge Univ. Press, 2008).

51. M. Domínguez-Rodrigo, S. de Juana, A. B. Galán, M. Rodríguez, A new protocol to differentiate trampling marks from butchery cut marks. J. Archaeol. Sci. 36, 26432654 (2009). doi:10.1016/j.jas.2009.07.017

52. R. J. Blumenschine, M. Selvaggio, Percussion marks on bone surfaces as a new diagnostic of hominid behaviour. Nature 333, 763-765 (1988). doi:10.1038/333763a0

53. T. R. Pickering, C. P. Egeland, Experimental patterns of hammerstone percussion damage on bones: Implications for inferences of carcass processing by humans. J. Archaeol. Sci. 33, 459-469 (2006). doi:10.1016/j.jas.2005.09.001

54. Q. Simon, D. L. Bourlès, N. Thouveny, C.-S. Horng, J.-P. Valet, F. Bassinot, S. Choy, Cosmogenic signature of geomagnetic reversals and excursions from the Réunion event to the Matuyama-Brunhes transition (0.7-2.14 Ma interval). Earth Planet. Sci. Lett. 482, 510-524 (2018). doi:10.1016/j.epsl.2017.11.021

55. S. J. Blott, K. Pye, Gradistat: A grain size distribution and statistics package for the analysis of unconsolidated sediments. Earth Surf. Process. Landf. 26, 1237-1248 (2001). doi:10.1002/esp.261

56. P. L. Folk, W. C. Ward, Brazos river bar [Texas]: A study in the significance of grain 
size parameters. J. Sediment. Petrol. 27, 3-26 (1957). doi:10.1306/74D706462B21-11D7-8648000102C1865D

57. J. R. Anderson, "Sand sieve analysis," in Historical Geology Online Laboratory Manual, P. J. W. Gore, Ed. (Department of Geology, Georgia Perimeter College, 2007).

58. D. Geraads, Kolpochoerus phacochoeroides (Thomas, 1884) (Suidae, Mammalia), du Pliocène supérieur d'Ahl al Oughlam (Casablanca, Maroc). Geobios 26, 731743 (1993). doi:10.1016/S0016-6995(93)80056-W

59. D. Geraads, New skulls of Kolpochoerus phacochoeroides (Suidae: Mammalia) from the late Pliocene of Ahl al Oughlam, Morocco. Palaeont. Afr. 40, 69-83 (2004).

60. M. Cherin, L. Sorbelli, M. Crotti, D. A. Iurino, R. Sardella, A. Souron, New material of Sus strozzii (Suidae, Mammalia) from the Early Pleistocene of Italy and a phylogenetic analysis of suines. Quat. Sci. Rev. 194, 94-115 (2018). doi:10.1016/j.quascirev.2018.06.029

61. R. L. Bernor, M. J. Armour-Chelu, H. Gilbert, T. M. Kaiser, E. Schulz, "Equidae," in Cenozoic Mammals of Africa, L. Werdelin, W. J. Sanders, Eds. (Cambridge Univ. Press, 2010), pp. 685-721.

62. V. Eisenmann, "Family Equidae," in Koobi Fora Research Project, Volume 2, The Fossil Ungulates: Proboscidea, Perissodactyla, and Suidae, J. M. Harris, Ed. (Clarendon Press Oxford, 1983), pp. 156-214.

63. J. van der Made, "The large mammals of the Plio-Pleistocene of Africa: Afrotheria, Perissodactyla and Artiodactyla I," in The Cradle of Humankind/La Cuna de la Humanidad, M. Domínguez Rodrigo, E. Baquedano, Eds. (Museo Arquelógico Regional and Museo de la Evolución Humana, 2014), pp. 324-336.

64. J. van der Made, M. Sahnouni, "Updated Plio-Pleistocene faunal lists for Ain Boucherit, Ain Hanech, and El Kherba sites, Algeria," in Proceedings of the International Symposium: Africa, Cradle of Humanity, Recent Discoveries, M. Sahnouni, Ed. (Centre National de Recherches Préhistoriques, Anthropologiques et Historiques, 2013), pp. 223-242.

65. C. S. Churcher, D. A. Hooijer, The Olduvai zebra (Equus oldowayensis) from the later Omo Beds, Ethiopia). Zool. Meded. 55, 265-280 (1980).

66. V. Eisenmann, "Les équidés des gisements de la Vallée de l'Omo en Éthiopie (collections françaises)," in Les faunes Plio-Pléistocènes de la basse Vallée de I'Omo, Éthiopie, Cahiers de paléontologie, Y. Coppens, F. C. Howell, Eds. (CNRS, Paris, 1985), pp. 13-55.

67. C. S. Churcher, Oldest ass recovered from Olduvai Gorge, Tanzania, and the origin of asses. J. Paleontol. 56, 1124-1132 (1982).

68. V. Eisenmann, Les metapodes d'Equus sensu lato (Mammalia, Périssodactyla). Geobios 12, 863-886 (1979). doi:10.1016/S0016-6995(79)80004-2

69. W. H. Gilbert, R. L. Bernor, "Equidae," in Homo erectus, Pleistocene evidence from the Middle Awash, Ethiopia, H. W. Gilbert, B. Asfaw, Eds. (Univ. California Press, Berkeley, 2008), pp. 133-166.

70. V. Eisenmann, D. Helmer, M. Sañia Segui, "The big Equus from the geometric kebaran of Umm el Tlel, Syria: Equus valeriani, Equus capensis, or Equus caballus?" in Archaeozoology of the Near East, Proceedings of the Fifth International Symposium on the Archaeozoology of Southwestern Asia and Adjacent Areas, H. Buitenhuis, A. M. Choyke, M. Mashkour, A. H. Al-Shiyab, Eds. (ARC Publicaties, Groningen, 2002), pp. 62-73.

71. T. Zingg, Beiträg zur Schotteranalyse. Schweiz. Mineral. Petrogr. Mitt. 15, 39-140 (1935).

72. M. Leakey, Olduvai Gorge. Excavations in Beds I \& II (Cambridge Univ. Press, 1971).

73. A. Delagnes, H. Roche, Late Pliocene hominid knapping skills: The case of Lokalalei 2C, West Turkana, Kenya. J. Hum. Evol. 48, 435-472 (2005). doi:10.1016/j.jhevol.2004.12.005 Medline

74. P.-J. Texier, "L'Oldowayen dans le Grand Rift occidental: le site NY18 à Nyabusosi, Ouganda," in Le Paléolithique en Afrique, L'Histoire la plus longue, M. Sahnouni, Ed. (Artcom'/Errance, Paris, 2005), pp. 83-98.

\section{ACKNOWLEDGMENTS}

We would like to thank the Algerian Ministry of Culture for the research permit; Professor S. Hachi Director of CNRPAH, the Wilaya of Sétif, the municipality of Guelta Zergua, Professors K. Guechi (President of the University of Sétif 2) and Y. Aibeche (Vice-President of the same) for administrative and logistic support during fieldwork at Ain Boucherit; CENIEH (Spain) staff especialy María José de Miguel del Barrio and Beatriz de Santiago Salinas for administrative support. MD is grateful to V. Guilarte and D. Martínez Asturias for their invaluable contribution in the ESR dating analytical procedure. Funding: Support by grants from CNRPAH, MINECO (HAR2013-41351-P), The L.S.B. Leakey Foundation, National Science Foundation (NSF-BCS-0517984), Wenner-Gren Foundation (Gr. 7815 and 8323), European Research Counsil (FP7-People-CIG2993581), Stone Age Institute (Bloomington, IN) to MS; MINECO (CGL2010-16821) to JMP and MD; Australian Research Council (FT150100215) to MD; European Science Foundation (Synthesys GB-TAF-4119 and DE-TAF-668) to JvdM, CGL201565387-C3-1-P (MINECO/FEDER) to JvdM and IC, and AGAUR (2017SGR1040), URV (2017PFR-URV-B2-91) to IC. Author contributions: MS was principal author and directed the project; JMP, MD led the geochronological research; APG, SA led geolological research, MS, ZH, AD, MM conducted the excavation and recovery of archaeological and fossil materials; MS, ZH, SS conducted the lithic analysis; JvdM, KB conducted the paleontological analysis; IC, NK conducted the taphonomical analysis. All authors participated in the writing of the manuscript. Competing interests: The authors have no competing interests. Data and materials availability: All data are available in the paper and supplementary materials, and the archaeological and paleontological materials are deposited in CNRPAH, Musée du Bardo, and Musée de Sétif in Algeria.

\section{SUPPLEMENTARY MATERIALS}

www.sciencemag.org/cgi/content/full/science.aau0008/DC1

Materials and Methods

Supplementary Text

Figs. S1 to S14

Tables S1 to S10

References (29-74)

26 April 2018; accepted 6 November 2018

Published online 29 November 2018

10.1126/science.aau0008 

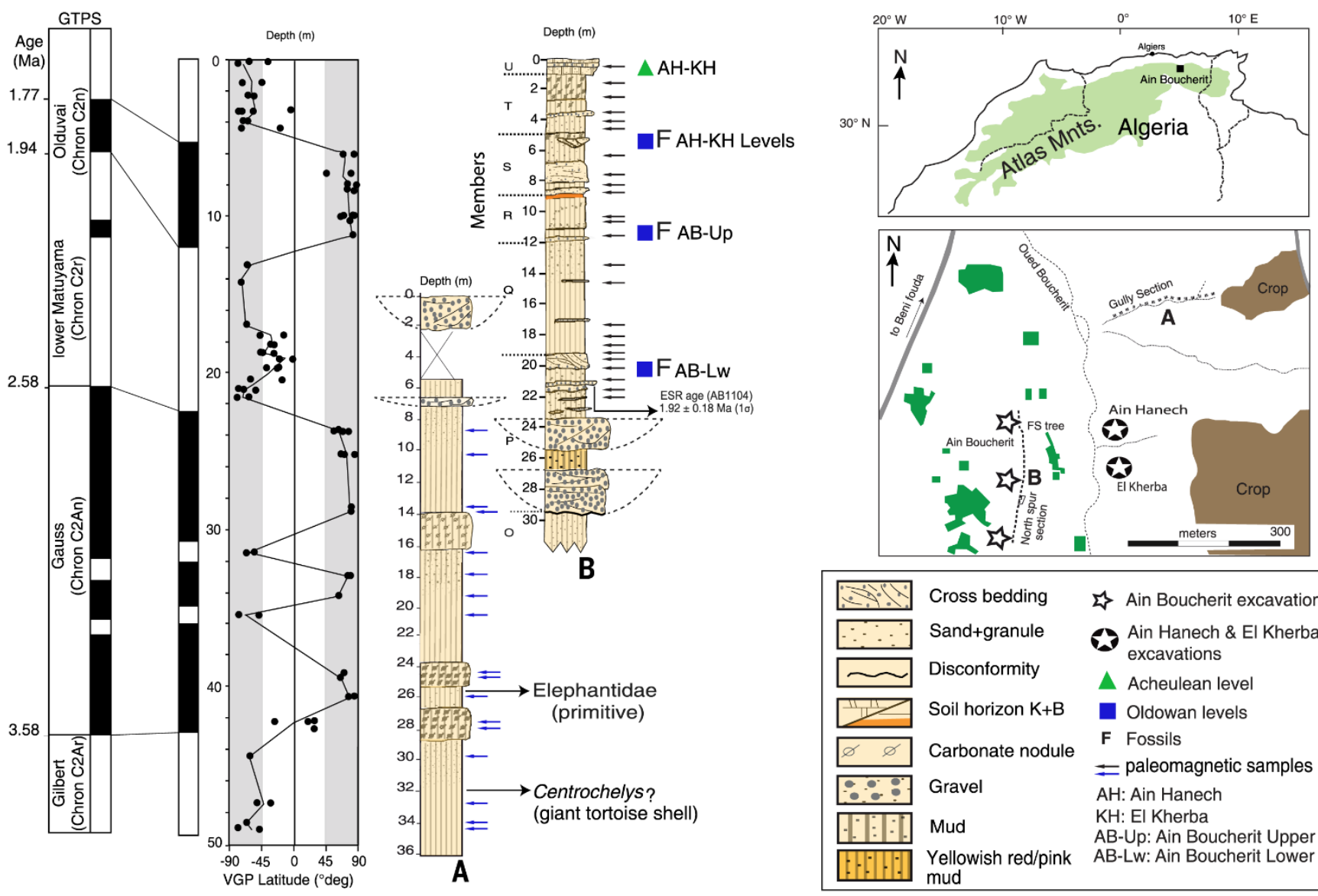

\begin{tabular}{|c|c|c|}
\hline & Cross bedding & Ain Boucherit excavations \\
\hline & Sand+granule & Ain Hanech \& El Kherba \\
\hline & Disconformity & $\Delta$ Acheulean level \\
\hline & Soil horizon $\mathrm{K}+\mathrm{B}$ & Oldowan levels \\
\hline$\varnothing \varnothing$ & Carbonate nodule & $\begin{array}{l}\text { F Fossils } \\
\neq \text { paleomagnetic samples }\end{array}$ \\
\hline & Gravel & $\mathrm{AH}:$ Ain Hanech \\
\hline 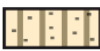 & Mud & $\begin{array}{l}\text { KH: El Kherba } \\
\text { AB-Up: Ain Boucherit Upper }\end{array}$ \\
\hline tin: & $\begin{array}{l}\text { Yellowish red/pink } \\
\text { mud }\end{array}$ & AB-Lw: Ain Boucherit Lower \\
\hline
\end{tabular}

Fig. 1. Location of Ain Boucherit, stratigraphy and magnetostratigraphic data of the site. Magnetostratigraphy is expressed with the Virtual Geomagnetic Pole (VGP) latitudinal position. Solid line connects the averaged VGP position when several specimens are used, and data from the upper $22 \mathrm{~m}$ (section B) modified from (9), while those below $22 \mathrm{~m}$ from section $A$. 


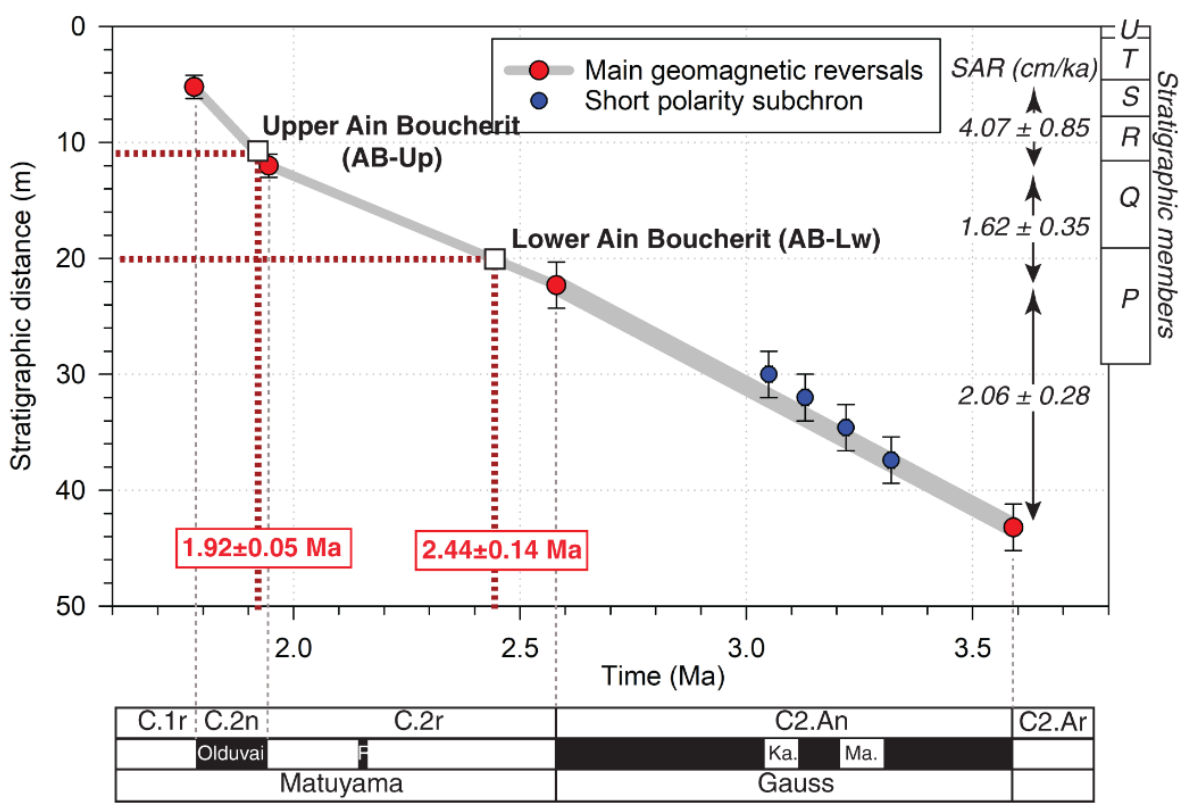

Fig. 2. Sediment accumulation rate values for the Ain Boucherit section and interpolated numerical ages obtained for $A B-L w$ and $A B-U p$. $A B-L w$ and $A B-U p$ are indicated with open squares. The thickness of the grey line and the vertical error bar on the individual points display the depth uncertainty (ca. $1 \mathrm{~m}$ from 0 to $22 \mathrm{~m}$ and ca. $2 \mathrm{~m}$ below). See further explanations in supplementary text S1 (12). SAR, sediment accumulation rate. 


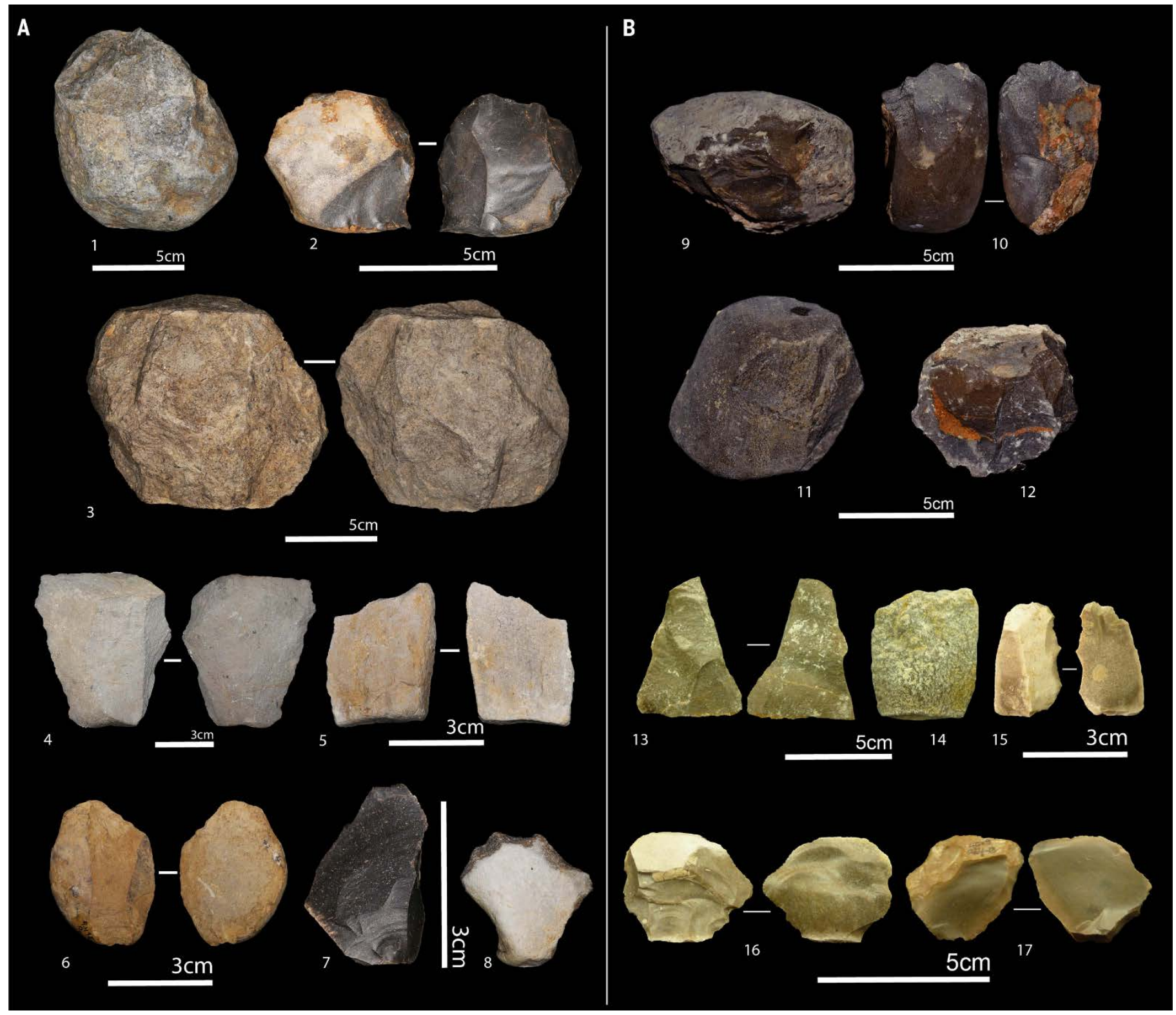

Fig. 3. Oldowan artifacts. (A and B) Oldowan artifacts from AB-Lw [(A), images 1 to 8$]$ and $A B-U p ~[(B)$, images 9 to 17$]$, including unifacial cores on limestone (1 and 9$)$; bifacial core made of limestone (10) and on flint (2); polyhedral cores on limestone (11 and 12); subspherical core on limestone (3); whole flakes on flint $(7,16$, and 17$)$ and on limestone (4, $5,6,13$, and 14); and retouched pieces on flint (8 and 15). 


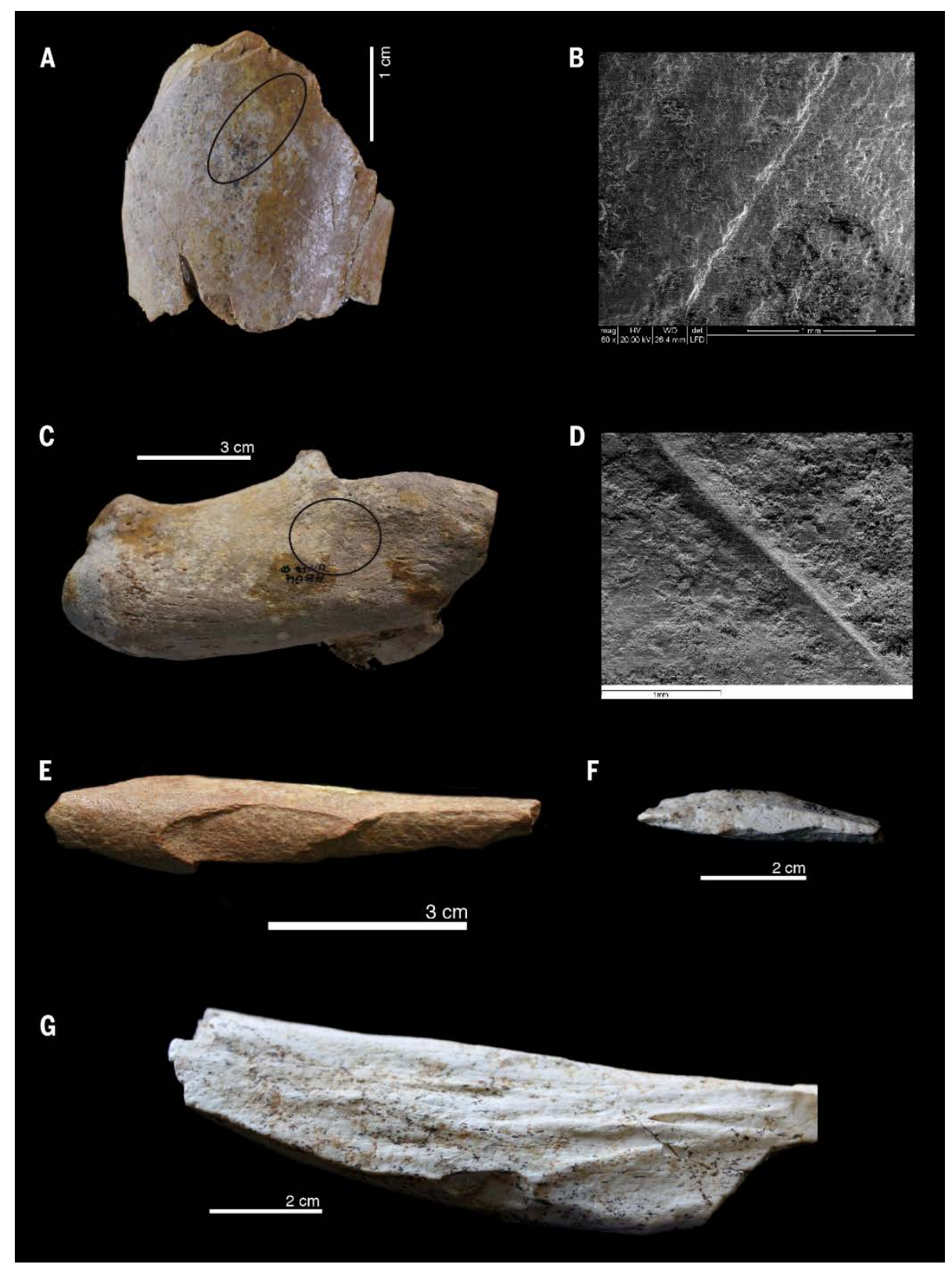

Fig. 4. Evidence of hominin activity from Ain Boucherit faunal assemblages. (A and $B$ ) Slicing mark on a medium size bovid humerus shaft from AB-Lw (A) with SEM micrograph detail (B). (C and D) Cutmarked equid calcaneum from AB-Lw (C) with SEM micrograph detail (D). (E) Hammerstone percussed medium size long bone from AB-Lw. (F) Bone flake from AB-Up. (G) Equid tibia from AB-Up showing cortical percussion notch. 


\title{
Science IIAAAS
}

\section{Supplementary Materials for}

\section{9-2.4 million-year-old artefacts and stone tool cutmarked bones from Ain Boucherit, Algeria}

\author{
Mohamed Sahnouni*, Josep M. Parés, Mathieu Duval, Isabel Cáceres, Zoheir Harichane, Jan \\ Van der Made, Alfredo Pérez-González, Salah Abdessadok, Nadia Kandi, Abdelkader Derradji, \\ Mohamed Medig, Kamel Boulaghraif, Sileshi Semaw
}

*Correspondence to: mohamed.sahnouni@ cenieh.es

This PDF file includes:

\author{
Supplementary Materials \\ Materials and Methods 1-3 \\ Supplementary Text S1-S5 \\ Figs. S1 to S14 \\ Tables S1 to S10 \\ (References 29-74)
}




\section{Materials and Methods}

1- Magnetostratigraphy (Figure S1) (JMP)

In a previous paleomagnetic study (9), we showed that sediments from the Ain Hanech Fm. are amenable for paleomagnetic studies. We therefore aimed to complement the chronology of the sediments by extending the initial magnetostratigraphy and locating additional magnetic reversals. We studied and sampled a new section ("Section A" in Fig. 1), which has a thickness of about 35 meters below the Ain Boucherit lower archaeological level (AB-Lw). The section is located NE of Ain Boucherit and follows an $\sim \mathrm{E}-\mathrm{W}$ trending gully that begins at the main drainage, Oued Boucherit. Section A starts below the reference section at ("northern spur") (29) and is characterized by a reddish clay-silt unit with abundant carbonate concretions towards the top. At about a height of $8 \mathrm{~m}$ from the bottom, the appearance of calcrete horizons begins. The clays become rather rich in carbonate concretions upwards. A conspicuous, $2.5 \mathrm{~m}$-thick calcrete layer is present at about a depth of $18 \mathrm{~m}$, which has distinct lateral continuity. Above this reference layer, carbonate concretions are more abundant within the clays, and at about 8 meters above a 1-meter thick poorly consolidated gravel appears. The section ends with a 2-m thick, well cemented gravel unit with heterometric clasts. Thus, the magnetostratigraphic study was carried out on sections A and B totaling $50 \mathrm{~m}$ thick profile beginning in the lowermost deposits about $20 \mathrm{~m}$ below $\mathrm{Mb} \mathrm{P}$ all the way up to the calcrete deposits in Mb U (Fig. 1).

\section{Methods}

Samples were taken in the field as small oriented $\sim 8$ cc blocks, typically three by horizon. Lithologies are usually friable materials and therefore the cubes were carefully carved in the field with the help of a ceramic knife and consolidated with a sodium silicate solution. Alternatively, when possible, $8 \mathrm{cc}$ plastic boxes were pushed onto the sediment. Either way samples were oriented in the field using a standard compass and clinometers.

All measurements were made at the Paleomagnetism Laboratory (CENIEH). Magnetic remanence including both natural remanent magnetization (NRM) and magnetization during cleaning were measured with a $755-4 \mathrm{~K}$ model superconducting rock magnetometer (2G Enterprises). The mouth of the magnetometer is placed in a large system of Helmholtz coils $(2.5 \mathrm{~m})$ to diminish the effect of the environmental magnetic field $(<300 \mathrm{nT})$. The magnetometer, with a noise level of less than $10^{-7} \mathrm{~A} / \mathrm{m}$ for a 10-cc volume rock, is equipped with a built-in Sample Degaussing System (2G600), allowing in-line alternating field demagnetization up to $170 \mathrm{mT}$ of standard specimens. Thermal demagnetization was carried out with an ASC Model TD48 furnace (single chamber), housed in the Helmholtz coils for further shielding. For each specimen, the best-fit line of the characteristic remanent magnetization (ChRM) component direction was calculated using principal component analysis (30), guided by visual inspection of orthogonal demagnetization plots (31). Mean directions and associated statistical parameters were estimated using Fisher's (1953) method. ChRM directions were used to calculate the Virtual Geomagnetic Pole (VGP) position at each sampling site, and the mean value of the VGP Latitude used to build a local magnetostratigraphy.

Specimens typically show a stable behavior upon demagnetization, producing reliable ChRM, antipodal directions (Fig. S1). Mean directions for both normal and reverse polarity are essentially antipodal, and even though a fold test is not possible, we are confident in that ChRM directions 
are of primary in origin. Further details on the paleomagnetic stability, including rock magnetism, can be found in (9). The new stratigraphic additional section expands our previous results by more than $100 \%$. Few meters below AB-Lw (at a depth of $\sim 8 \mathrm{~m}$ ) the polarity is dominantly normal for about 21 meters, where the next normal to reverse polarity change occurs. The long normal polarity chron is truncated by two short reverse intervals, at depths of 16 and $21 \mathrm{~m}$, respectively. Such polarity intervals are each based on one single sampling site, but the ChRM directions are reliable. In our previous study we discussed the interpretation of the upper part of the section, where the Olduvai Subchron was identified (9), and therefore, the most plausible explanation for the lower normal magnetozone is the Gauss Chron (meters 22 to 43, see Fig. 1). The two short reverse intervals within Gauss could tentatively be interpreted as Kaena and Mammoth, respectively.

2- Electron Spin Resonance dating of optically bleached quartz grains from Aïn Boucherit locality (Algeria) (Figures S2 and S3; Tables S1-S4) (MD)

\section{Methods}

Sampling and sample preparation

Several sediment samples have been collected in July 2011 from the Aïn Boucherit section, but only one (AB1104) had yielded sufficient quartz material for ESR dating. To access fresh and undisturbed deposits, a few-meters deep trench was specifically excavated for this purpose. AB1104 was collected from a silty level stratigraphically located $<1 \mathrm{~m}$ below the Lower archaeological level (Fig. S2). Gamma dose rate was assessed in situ by means of a NaI probe at the exact same ESR sampling spot, and additional sediment was collected for further laboratory analysis.

AB1104 was prepared in the laboratory under conditions of limited illumination and following the standard procedure at CENIEH. The 100-200 $\mu \mathrm{m}$ size fraction was collected after wet sieving. $\mathrm{HCl}(36 \%)$ was used to dissolve carbonates and $\mathrm{H}_{2} \mathrm{O}_{2}(30 \%)$ to eliminate organic matter. Heavy minerals and feldspars were removed with Sodium Polytungstate solutions at $\mathrm{d}=2.72$ and $\mathrm{d}=2.62$ $\mathrm{g} / \mathrm{ml}$, respectively. Then, magnetic minerals were eliminated using neodymiun magnets. The resulting samples were treated with $\mathrm{HF}(40 \%)$ for 40 minutes to eliminate the remaining feldspars and to etch quartz grains. Finally, $\mathrm{HCl}(18 \%)$ was added in order to remove any soluble fluoride.

\section{ESR dose evaluation}

AB1104 was dated by using the Multiple Aliquots Additive (MAA) dose method and following the Multiple Centre approach, as in (32). The natural sample was divided into 14 aliquots. Twelve aliquots were irradiated using a Gammacell-1000 ${ }^{137} \mathrm{Cs}$ gamma source (dose rate $=6.9 \mathrm{~Gy} / \mathrm{min}$ ) at the following doses: 200.2, 350.3, 550.5, 900.8, 1401.2, 2301.9, 4003.3, 6005.2, 10008.5, 17014.2, 25020.7 and 40040.3 Gy. The non-bleachable residual ESR signals of the Aluminium centre were obtained after exposing one aliquot of each natural sample in a SOL2 (Dr Hönle) solar light simulator for about $1460 \mathrm{~h}$.

ESR measurements were carried out at CENIEH, with an EMXmicro 6/1Bruker X-band ESR spectrometer coupled to a standard rectangular ER 4102ST cavity. To ensure constant experimental conditions over time, the temperature of the water circulating in the magnet is controlled and stabilized at $18^{\circ} \mathrm{C}$ by a water-cooled Thermo Scientific NESLAB ThermoFlex 3500 
chiller, and the temperature of the room is kept constant at $20^{\circ} \mathrm{C}$ by an air conditioning unit. ESR measurements were performed at low temperature $(\sim 90 \mathrm{~K})$ using an ER4141VT Digital Temperature control system based on liquid nitrogen cooling. See (33) for further details about the setup and about its stability over time.

In accordance with the Multiple Centre (MC) method first defined by (16), the ESR signals of both the $\mathrm{Al}$ and $\mathrm{Ti}$ centres were measured in the sample. For the first one, the following acquisition parameters were used: $10 \mathrm{~mW}$ microwave power, 1024 points resolution, $20 \mathrm{mT}$ sweep width, 100 $\mathrm{kHz}$ modulation frequency, $0.1 \mathrm{mT}$ modulation amplitude, $40 \mathrm{~ms}$ conversion time, $10 \mathrm{~ms}$ time constant and 1 scan. In contrast, the ESR signal associated to Ti centres was measured as follows: $5 \mathrm{~mW}$ microwave power, 1024 points resolution, $20 \mathrm{mT}$ sweep width, $100 \mathrm{kHz}$ modulation frequency, $0.1 \mathrm{mT}$ modulation amplitude, $60 \mathrm{~ms}$ conversion time,10 ms time constant and 1-3 scans. Each of the fourteen aliquots (one natural, one optically bleached and twelve gamma irradiated aliquots) was measured 3 times after a $\sim 120^{\circ}$ rotation in the cavity for both $\mathrm{Al}$ and $\mathrm{Ti}$ signals, in order to consider angular dependence of the signal due to sample heterogeneity. Then measurements were repeated three times over distinct days in order to check the variability of the DE values.

The ESR intensity of the Al signal was extracted from peak-to-peak amplitude measurements between the top of the first peak $(\mathrm{g}=2.0185)$ and the bottom of the 16th peak $(\mathrm{g}=1.9928)(34)$. Following the conclusions from (35), the ESR intensity of the Ti centres was measured in three different ways (Fig. S3):

- Peak-to-peak amplitude measurement between $g=1.979$ and the bottom of the peak at $\mathrm{g}=1.913$ (option A).

- Peak-to-baseline amplitude measurement around g=1.913-1.915 (option D).

- Peak-to-baseline amplitude measurement around g=1.915 (Option C, Ti-H centre).

For each aliquot, final ESR intensities of $\mathrm{Al}$ and $\mathrm{Ti}$ centers corresponded to the mean values derived from the repeated measurements, previously corrected by the corresponding receiver gain value, number of scans, aliquot mass and a temperature correction factor (33).

The fitting procedures were carried out with the Microcal OriginPro 8.5 software using a Levenberg-Marquardt algorithm by chi-square minimization. For the $\mathrm{Al}$ center, an exponential+linear function (EXP+LIN) was fitted through the experimental points, and data were weighted by the inverse of the squared ESR intensity $\left(1 / \mathrm{I}^{2}\right)$. DE values were obtained by extrapolating the EXP+LIN function to the residual intensity (so called Total bleach method [36]). For the Ti centre, the Ti-2 function was used (35) in order to describe the non-monotonic dose dependence of the ESR signal at high doses. Data were weighted by the inverse of the squared experimental error $\left(1 / \mathrm{s}^{2}\right)$ and $\mathrm{DE}$ values were obtained by back extrapolation to the $\mathrm{Y}=0$. Final ESR dose response curves (DRCs) are shown in Fig. S3.

\section{Dose rate evaluation}

The total dose rate value was derived from a combination of in situ and laboratory measurements. External gamma dose rate was assessed in situ with a NaI probe connected to an Inspector-1000 multichannel analyser and calculated using the "threshold" technique (37). Radioelement (U, Th, $\mathrm{K})$ concentrations in the sediment were determined by ICP-OES/MS analysis of about $5 \mathrm{~g}$ of dry 
raw sediment. In addition, $\sim 150 \mathrm{~g}$ of this same raw sediment, previously dried and powdered, were analysed by High Resolution Gamma Spectrometry (HRGS) using a Canberra Extended Range (XTra) HpGe detector in order to identify possible disequilibrium in the U-238 decay chain. Concentration values were used to derive external alpha and beta dose rate components using the dose rate conversion factors from (38). Dose rate values were calculated assuming a mean grain size of $150 \mu \mathrm{m}$ and a thickness removed by HF etching of $20 \mu \mathrm{m}$. Internal dose rate was considered to be $50 \pm 30 \mathrm{uGy} / \mathrm{a}$ based on the work from (39) and on an alpha efficiency k value of $0.15 \pm 0.10$. Values were corrected with beta and alpha attenuations for spherical grains $(40,41)$ and water attenuation formulae from (42). Current water content was evaluated in the laboratory by drying the sediment at $50^{\circ} \mathrm{C}$ in an oven for three weeks. A value of $5.6 \%$ (wet weight) was obtained. This, however, is most likely underestimated in comparison with the past water content, not only because the sample was collected during the dry summer season, but also because past sediment overburden was significantly thicker and paleoclimate conditions were more humid than today. Consequently, a value of $20 \pm 5 \%(1 \sigma)$ was assumed instead as being more representative of the long-term water content. The large associated error covers a range of 10 to $30 \%$ at $2 \sigma$, covering thus possible significant fluctuations of water content over time. The cosmic dose rate was calculated using formulae from (43), with depth, altitude and latitude corrections (44). Current depth below surface is $<3 \mathrm{~m}$. However, this value most likely underestimates the long-term depth of the sample given the thickness of the sedimentary sequence. Because the sediment overburden is estimated to be at least $20 \mathrm{~m}$ (Fig. 1), a value of $20 \pm 5 \mathrm{~m}$ was considered for the ESR age calculation.

ESR age calculation were performed using a non-commercial SCILAB based software, with error calculations based on Monte Carlo simulation, considering the following sources of uncertainties: concentrations, depth, water content, gamma dose rate, beta dose attenuation, DE values. ESR ages are given at $1 \sigma$.

\section{Results and discussion $D_{E}$ determination}

Analytical results show overall robust ESR data and reliable fitting results for both $\mathrm{Al}$ and $\mathrm{Ti}$ centres. Measurement and $\mathrm{D}_{\mathrm{E}}$ repeatability are within the standards, while both ESR DRCs show an excellent goodness-of-fit, with adj. $\mathrm{r}^{2}>0.99$ (Table S1), which is actually not so frequent for the Ti-Li centre (e.g. 35). The Al centre yields a $\mathrm{D}_{\mathrm{E}}$ value of $2282 \pm 169 \mathrm{~Gy}$, while the Ti-Li centre provides a slightly higher result by $6 \%(2418 \pm 129 \mathrm{~Gy})$. Those $\mathrm{D}_{\mathrm{E}}$ values are in close agreement. Following the principles of the MC approach, these results suggest that the Al signal has been reset to its residual level during sediment transportation. Consequently, the weighted mean $\mathrm{D}_{\mathrm{E}}$ value of $2368 \pm 103$ Gy most likely represents the best estimate for the burial dose of AB1104.

For information, the Ti signal option A provides a consistent value with option D (2548 \pm 348 Gy) indicating that the peak at $g=1.979$ (Ti-H signal) has very little influence on the dose estimate derived from Ti-Li Option D signal. In contrast, the Ti-H centre yields a significantly lower $\mathrm{D}_{\mathrm{E}}$ value of $1059 \pm 186 \mathrm{~Gy}$. The accuracy and reliability of this estimate may nevertheless be reasonably questioned for two main reasons. First, goodness-of-fit is not as good as that achieved for $\mathrm{Al}$ and Ti-Li option D signals (adj. $\mathrm{r}^{2}<0.97$ ). Then, this signal is known to saturate earlier with the dose than the other signals and is apparently not able to provide accurate dose values for $\mathrm{D}_{\mathrm{E}}>$ 
$1000 \mathrm{~Gy}$. Instead, the characteristics of the Ti-H signal make it extremely promising for samples younger than $300 \mathrm{ka}$ but so far unreliable for older chronologies (e.g. 32, 45).

\section{Dose rate evaluation}

Sediment was analyzed in situ as well as in the laboratory by two different techniques. ICP OES/MS analyses were performed on $\sim 10 \mathrm{~g}$ of raw sediment in order to obtain $\mathrm{U}$, Th and $\mathrm{K}$ concentrations (Table S2). Additional High-resolution gamma spectrometry (HRGS) analysis carried out on raw dry sediment sample $(\sim 150 \mathrm{~g})$ did not show any significant disequilibrium within the U-238 series decay chain. Both techniques yield consistent results at $1 \sigma$, indicating thus the homogeneity of the sediment in the immediate vicinity (a few centimeters around) of the dated sample.

A comparison of the gamma dose rates derived from in situ and laboratory analyses is shown in Table S3. As expected, laboratory values obtained from ICP and HRGS measurements are highly consistent and range from 650 to $700 \mu \mathrm{Gy} / \mathrm{a}$. Those values are however significantly higher than the in situ estimated. This difference is very likely due to the heterogeneity of the sedimentary environment within a $\sim 30 \mathrm{~cm}$-radius sphere around the sample, highlighting thus the importance to carry out in situ measurements at the exact location of the sampling spot.

\section{Age results}

ESR age estimates were calculated using the $\mathrm{D}_{\mathrm{E}}$ values derived from both the $\mathrm{Al}$ and Ti-Li centres, gamma dose rates measured in situ and beta dose rate derived from ICP OES/MS, and assuming constant equilibrium in the U-series decay chain. A water content value of $20 \pm 5 \%$ was considered. Given the thickness of the sedimentary sequence (Fig. 1), a depth of $20 \pm 5 \mathrm{~m}$ was used.

ESR age calculation provides consistent highly consistent results for the two centers (Table S4). Consequently, we consider the combined Al-Ti age of $1.92 \pm 0.18 \mathrm{Ma}(1 \sigma$ confidence level) as the best estimate for AB1104. Stratigraphically located below the lower archaeological level, this sample provides a maximum age of $2.28 \mathrm{Ma}$ (considering the $2 \sigma$ upper limit of the ESR combined age) for the hominin occupation.

This age calculation was performed using the most reasonable assumptions for some of the parameters. However, one may be aware that for such a long time range those assumptions might actually have a non-negligible influence on the final results. In particular, we identify two main sources of uncertainty whose impact on the final age results should be further investigated: water content and depth.

For example, increasing or decreasing the average water content value of $5 \%$ (i.e. $15 \pm 5 \%$ and $25 \pm 5 \%$ ) would lead to the variation of $-6 \%$ and $+7 \%$ of the final age estimate, respectively. The resulting age would thus remain within error, and we consider the value of $20 \pm 5 \%$ as the most reasonable estimate, as it covers a range of $10-30 \%$ at a $2 \sigma$ level, which most likely encompasses the long-term water content variability.

The depth is also another important source of uncertainty worth considering. A $20 \pm 5 \mathrm{~m}$ depth was used for the age calculation, which may be considered as conservative estimation based on the average thickness of the sedimentary deposits overlying the lower archaeological level of Ain Boucherit. However, this value might potentially be quite underestimated given the massive 
erosion that is affecting the basin. If the current depth of the sample below the ground surface was estimated to be around $3 \mathrm{~m}$, one may reasonably consider this value as meaningless for accurately estimating the time average cosmic dose rate. Actually, the geomorphology and the remaining deposits located on the eastern side of the studied deposits suggest that sub-recent fluvial incision has eroded at least $25 \mathrm{~m}$ of sediment, from which we may estimate that the maximum thickness of the sediment cover above the sample was very likely around $25-30 \mathrm{~m}$, which is actually covered by the value used for age calculation $(20 \pm 5 \mathrm{~m}$, corresponding to a depth range of $10-30 \mathrm{~m}$ at a $2 \sigma$ level). When considering the most extreme scenario, i.e. by assuming the absence of cosmic dose rate has prevailed over the burial history of the sample, the ESR age would increase by $+1.7 \%$ and be of $1950 \pm 180 \mathrm{ka}$. Consequently, the impact of the cosmic dose rate on the ESR age result is apparently limited.

One may note that the final combined Al-Ti age of $1.92 \pm 0.18 \mathrm{Ma}$ appears to be somewhat younger than the corresponding inferred SAR age estimate. This apparent discrepancy is due to the existing uncertainty on the dose rate evaluation (see above) or on the SAR estimate, or most likely from a combination of both. Full discussion may be found in supplementary text S1.

Despite its inherent uncertainty, this ESR age estimate unambiguously indicates that the reverse magnetozone in the lower part of the Ain Hanech Formation corresponds to the early Matuyama chron (C2r), which is chronologically constrained between 1.94-2.58 Ma. This result enables to discard possible correlations of the normal magnetozone including AB-Up to positive subchrons other than Olduvai.

Finally, from a methodological point of view this work has probably produced the oldest ESR age with the MC approach. The overall consistency between the ESR results derived from each centre and the independent magneto-bio-stratigraphic framework may also be considered as an empirical evidence that the Ti-Li centre can provide reliable results up to $\sim 2 \mathrm{Ma}$, which is consistent with previous observations (46). Lastly, this encouraging result also shows the suitability of the quartz material from the Ain Boucherit area for ESR dating, and definitely opens the possibility for collecting more samples along the sequence in the future.

\section{3- Taphonomy of AB-Lw and AB-Up faunal assemblages (Figure S4; Tables S5-S7) (IC; NK)}

\section{Methods}

The faunal remains were analyzed anatomically and taxonomically. Whenever possible, an estimated age at death (immature, adult) was indicated, using criteria of tooth eruption and tooth wear, and epiphyseal fusion. When taxonomical identification was not possible, we have used mammal size groups modified from $(47,48): 1)$ very small size $(<20 \mathrm{~kg}) ; 2)$ small size $(20-100$ $\mathrm{kg})$; 3) medium size (100-300 kg); 4) large size (300 - $1000 \mathrm{~kg})$; and 5) very large size (> 1000 $\mathrm{Kg}$ ). Similarly, to include non-anatomically identifiable fragments, the bones are classified into long bones (limbs), flat bones (axial and cranial skeleton), and articular bones (carpals, tarsals, epiphysis fragments).

All bones have been analyzed macroscopically and microscopically, using a stereomicroscope (Optech-LFZ x45) and ESEM (Fei-Quanta 600) when was necessary. In some cases, silicone casts (Provil Novo Heraeus Light) and polyurethane resin (Feropur PR-55/E-55) have been made to observe the modifications with SEM (Scanning Electron Microscope Jeol-6400). All 
biostratinomic and fossil-diagenetic modifications have been recorded based on presence/absence, modification type, location on bone surface, organization (isolated, concentrated, scattered or generalized), and when necessary, disposition (longitudinal, transversal, oblique), and dimensions.

Hominin activities have been identified based on evidence of cutmarks and bone breakage for marrow extractions. We analyzed the type of cutmark (mainly slicing marks and scraping marks), their locations on bone surfaces, their distributions, and their orientations (49-51) for identifying the activity of butchery processes carried out by hominins (25). Hominin involvement in bone breakage has been recorded by the presence and location of hammerstone percussion pits, medullary or cortical percussion notches, and bone flakes $(52,53)$

\section{Results}

The 573 fossils recovered in AB-Lw (Mb P) (296) and AB-Up (Mb R) (277) belong to several bovid species, mainly small size bovids (gazelles and parantidorcas) followed by equids. The very small and medium sized animals are the most abundant while the large and very large ones are scarcer (Tables S5, S6). In both archaeological levels carnivore fossils are scarce. A total of 33 MNI have been identified, 19 in AB-Lw and 14 in AB-Up. Except for small sized animals, the majority of animal size groups present a biased skeletal representation. The appendicular remains are the most represented, followed by cranial and axial bones in both levels. The axial remains are more abundant in AB-Lw than AB-Up. As for the appendicular skeleton, the lower elements (metapodial, phalanges and carpal-tarsal) are the most abundant.

Bone modifications have been identified in both fossil assemblages (Fig. S4). The main modification agents were post-depositional, both biostratinomic and fossil-diagenetic (i.e. oxide stain, rounded and polish, cracks and root etching). These modifications are common in open air environments and have a lower incidence in $\mathrm{AB}-\mathrm{Lw}$, which generally presents a better preservation of bone surfaces than in AB-Up. Water abrasion (rounding and polishing) is one of the most important post-depositional bone modifications in AB-Up, but no sorting of abraded elements has been observed and modifications appear mainly moderate. In AB-Lw assemblage, abrasion is barely present, which could be related to low energy flows, where the bones could be modified as passive objects without their displacements, because abrasion does not affect completely fossil surfaces. For AB-Up, where abrasion is more present, local rearrangement of bones could have occurred.

In both levels, both hominin (cutmarked and hammerstone-percussed bones) and carnivore activities (toothmarks) have been documented. The incidence of these agents in each of the levels is different. Whereas in $\mathrm{AB}-\mathrm{Lw}$ hominin activity is higher, carnivores were the primary agents at AB-Up. The location of cutmarks (following, 25), in AB-Lw and AB-Up allowed the identification of butchering activities developed by hominins. Thus, skinning, evisceration, and defleshing activities have been observed (Table S7). Hominin marrow exploitation is present mainly in medium-sized animals in AB-Lw and in large and medium-sized animals in AB-Up.

The Ain Boucherit bone assemblages of AB-Lw and AB-Up have provided clear evidence of hominin meat and marrow consumption from several ungulates, mainly small-sized bovids and equids. Hominin exploitation of animals include skinning, evisceration, and defleshing activities 
in AB-Lw and defleshing in AB-Up. These activities, mostly evisceration (25), suggest an early hominin access to animal carcasses (26). The hammerstone-percussed bones are related to marrow consumption suggesting that hominins exploited all animal resources. In addition, the scarcity of carnivore toothmarks corroborates the main involvement of hominins in accessing animal carcasses, and a low hominin-carnivore interaction, especially in AB-Lw. In level AB-Up, the carnivore activity is more abundant indicating a hominin-carnivore competition greater than level AB-Lw. However, the absence of carnivore toothmarks in the axial skeleton and evidence of cut marks and hominin bone breakage in several bones, suggest primary access by hominins, at least to some carcasses. 


\section{Supplementary Text}

S1: Chronological inferences for Ain Boucherit lower and upper archaeological levels (Figure S5) (MD; JMP)

The magnetostratigraphic study of the deposits led to the identification of a succession of Normal and Reverse polarity intervals. The ESR age estimate of $1.92 \pm 0.18 \mathrm{Ma}(1 \sigma$ confidence level) obtained for a sample located just below the lower archaeological level (AB-Lw) enables to anchor the local magnetic stratigraphy to the Geomagnetic Polarity Time Scale (GPTS) and hence to correlate the upper normal interval to the Olduvai Chron (1.77-1.94 Ma) (15), while the lower ca. 20 m-thick dominantly normal magnetozone can confidently be attributed to the Gauss Chron (2.58-3.58 Ma) (Fig. 1). These correlations are supported by the biochronological evidence (see SM [S4]). The combination of these two-independent approaches, ESR and biochronology, enables to establish a rather robust chronostratigraphic framework, positioning the Ain Boucherit upper level (AB-Up) within the Olduvai Subchron (1.77-1.94 Ma), while AB-Lw has a preOlduvai age, somewhere between 1.94 Ma and 2.58 Ma. As of now, the inherent uncertainty of the ESR age estimate (see Discussion in Material and Methods 2) combined with a single sample precludes to constrain any further the chronology of AB-Lw.

Nevertheless, given the number of geomagnetic reversals observed along the sequence, the age of the two archaeological levels may also be inferred from the sediment accumulation rate (SAR) values (see Fig. 2). The overall uncertainty on the SAR values has been estimated by considering the individual uncertainty on the depth and on the age of the geomagnetic reversal ages (15), which have then been propagated into the final SAR value, as follows:

- The duration of the geomagnetic boundaries has been taken from (54), with 4 and 8 ka for the top and bottom of Olduvai, respectively. For the older reversals, a value of $7 \mathrm{ka}$ has been considered based on the mean value derived from the excursions within the Matuyama chron. These values are considered as a reasonable estimate of the uncertainty on the age of the geomagnetic polarity reversals.

- The uncertainty on the depth values has been derived from the paleomagnetic sampling resolution along the composite sequence, which significantly varies from the bottom to the top of the sequence (Fig. 1): from a depth of $49 \mathrm{~m}$ to $22 \mathrm{~m}$, the resolution is estimated to be of 1 sample per $2 \mathrm{~m}$ ( 14 samples over $27 \mathrm{~m}$ ), while it increases to 1 sample per $1 \mathrm{~m}$ for depths from 22 to $0 \mathrm{~m}$ (24 samples over $22 \mathrm{~m})$.

From the bottom of Gauss to the base of Olduvai, SAR values are within error $(2.06 \pm 0.28 \mathrm{~cm} / \mathrm{ka}$ and $1.62 \pm 0.35 \mathrm{~cm} / \mathrm{ka}$ ). This almost constant sedimentation rate is additionally supported by the position of two short reverse polarity subchrons that have been tentatively attributed to Mammoth and Kaena and which fit within error with the regression line from the bottom to the top of Gauss. During Olduvai, an acceleration of the sedimentation rate can be observed, with a mean SAR value multiplied by a factor of 2 . The age of both $\mathrm{AB}-\mathrm{Lw}$ and $\mathrm{AB}-\mathrm{Up}$ may be interpolated from the SAR values, resulting in $2.44 \pm 0.14 \mathrm{Ma}$ and $1.92 \pm 0.05 \mathrm{Ma}$, respectively. 
In correlating sections A and B, we used the classic "Jacob's staff" (1.5 m rod that includes an Abney level on top) to measure bed thicknesses in the field and therefore to trace beds from one section to the other across a creek for a distance of 400 meters. Based on our field observations, we are confident to confirm the absence of evidence of faulting in the study area, tilting as strata are virtually flat-lying, and cut-and-fill structures and disconformities. However, in spite of our confidence in the stratigraphic correlation between sections A and B, we do acknowledge there is an intrinsic uncertainty, related to the position of the Gauss-Matuyama (G-M) boundary (2.58 Ma) given the origin of the palaeomagnetic data (section B: all data above a depth of $22 \mathrm{~m}$; section A: all data below 22m; see Fig. 1). Consequently, this may have a non-negligible impact on the inferred age for $\mathrm{Ab}-\mathrm{Lw}$ (unlike AB-Up, whose age is inferred from the SAR estimate for the Olduvai subchron), which is magnetostratigraphically located between the G-M (2.58 Ma) and Matuyama-Olduvai (1.94 Ma) boundaries. Our SAR estimates already included an uncertainty of $2 \mathrm{~m}$ (considered as a reasonable estimate) in the depth of the Gauss-Matuyama boundary. To evaluate the impact of this uncertainty on the inferred age estimate for AB-Lw, we can in first instance consider two additional extreme scenarios in which the G-M boundary would be either 4 $\mathrm{m}$ above than initially considered (scenario 2), or $4 \mathrm{~m}$ below (scenario 3). The resulting interpolated age for AB-Lw would be of $2.75 \pm 0.32$ Ma for scenario 2 (see Fig. S5). This is in clear contradiction with the magnetostratigraphic evidence positioning AB-Lw within a reverse Chron and providing a maximum age constraint of $2.58 \mathrm{Ma}$. Consequently, scenario 2 can be reasonably discarded. For scenario 3 , a SAR age estimate $2.30 \pm 0.08 \mathrm{Ma}$ may be derived. This age result is $6 \%$ younger than initially calculated, but nevertheless remains within error with our initial calculation (scenario 1).

Alternatively, another option (scenario 4) would be to extrapolate an age for AB-Lw from the SAR estimate obtained for the Olduvai subchron $(4.07 \pm 0.85 \mathrm{~cm} / \mathrm{ka})$. This option has the advantage to be totally independent of the position of the G-M boundary. A resulting age of $2.14 \pm 0.05 \mathrm{Ma}$ may be obtained (i.e. about $9 \%$ lower than the result from scenario 3), which may be considered as the minimum possible age for AB-Lw, however, it is not supported by biochronologically significant fauna, especially of Equus, whose FAD in Eastern Africa (Member G, Omo, Ethiopia) is $2.32 \mathrm{Ma}$ (61) and even 2.6 Ma (as implied by Eisenmann) (62) based on material from Zone C in Koobi Fora (Kenya). To conclude, we consider the interpolated age of $2.44 \pm 0.14 \mathrm{Ma}$ as the most reasonable estimate for $\mathrm{Ab}-\mathrm{Lw}$, although we acknowledge that it might be slightly younger given the existing uncertainty on the correlation between sections $\mathrm{A}$ and $\mathrm{B}$.

In summary, the use of four chronostratigraphic tie-points (top and bottom of Gauss Chron and top and bottom of Olduvai Subchron) provides a robust age model that contributes to refining the age estimate of the archaeological levels. Given the intrinsic uncertainty on the age model and interpolation, an age of $\sim 1.9$ and $\sim 2.4$ Ma may thus be proposed for the Upper and Lower Ain Boucherit levels, respectively.

\section{S2: Stratigraphy (APG)}

The Ain-Hanech sites are contained in the Mio-Plio-Pleistocene sub-basin of Beni Fouda located to the northeast of the Sétif region (Eastern Algeria). It forms part of the larger continental setifian sedimentary basin that extends throughout the Eastern Algerian High Plateaus. The Beni Fouda sub-basin is open to the south-east (El Eulma) and is bordered by the Mesozoic and lower Tertiary 
Tell reliefs from the Djemila anticline to the north-east, Djebel Medjounes to north-west, and Oulad Sabor to the south-west. On the upper reaches of Ain Boucherit valley, the sub-basin contains the $100 \mathrm{~m}$ thick informal Oued Laatach Formation, on top of which rests, on an erosive disconformity, the Ain Hanech Formation of Lower Pleistocene age (29). The revised Ain Hanech Formation is $29 \mathrm{~m}$ thick and includes, from bottom to top, 6 members: P, Q, R, S, T and U, which seals the formation.

At the basal end of the Ain Hanech Fm is Member P overlying the top of Oued Laatach Fm (O). The $10 \mathrm{~m}$ thick lower part is composed of river channel facies dominated by gravel and flood plain deposits of pink color (7.5 YR 7/4) or yellow red (5YR $5 / 6)$. The upper part (4 m) is equally muddy, although with a higher content of clay than the lower part with sandy intercalations and gravels, also in fluvial system but of smaller channels. The directions of flow of sediments, measured in the internal structures of the channels, indicate the directions $20^{\circ} \mathrm{N}$ and $120^{\circ} \mathrm{N}$ for these higher facies. The current of the lower deposit indicates a NE-SW direction. The Ain Boucherit lower archaeological level (AB-Lw) is encased in this part of $\mathrm{Mb} \mathrm{P}$. The following Member Q is $7 \mathrm{~m}$ thick and consists of a monotonous series of flood plain sediments with high clay content (50-60\%), color brown light/brown (7.5 YR 5.6 / 4), and fine-grained upwards sequence (with less sands towards the top). Immediately above Q, rests Member R, whose 10-15 $\mathrm{cm}$ thick base consists of sandy mud of light brown color (7.5 YR), and homometric scatter gravels of pebble size or small cobbles that diminish in thickness towards the south. This level, along with the overlain $25 \mathrm{~cm}$ thick very pale brown sandy mud (10 YR8 / 2), contains lithic industry and fossil fauna (corresponding to the Ain Boucherit upper archaeological level [AB-Up]). Member R is capped by a light brown mud (7.5 YR6 / 3). These deposits are associated with fluvial gravels and flood plain facies under seasonal flooding conditions. The upper part of the formation includes Members S, T and U. Member S is $4 \mathrm{~m}$ thick and consists of light brown mud (7.5 YR 674) of channel facies with sand and fine or mid-size pebbles. The flow is N-S with direction to the south. This member presents edaphic $\mathrm{Ca} \mathrm{CO} 3$ nodulations towards the top. Member $\mathrm{T}$ is $4 \mathrm{~m}$ thick, and is mainly a muddy unit, light brown (7.5 YR6 / 4) or pink (7.5 YR7 / 4) color with very hard $\mathrm{CaCO}_{3}$ nodulations in its final $2 \mathrm{~m}$, which come from the migration of carbonates of the overlying Member U. Member T contains the younger Oldowan horizons of Ain Hanech and El Kherba (29). Member $U$ is $0.75-0.80 \mathrm{~m}$ thick and is composed of detrital facies of sands and gravels of fluvial origin indurated by up to $80 \%$ of carbonates, which gave rise to a K horizon that stands out in the landscape. This member yielded Acheulean stone tools.

In summary, the Ain Hanech Fm represents a fluvial sequence of braided rivers with pebble and cobble bottom loading transport. Its initial $10 \mathrm{~m}$ thickness consists of floodplain deposits with very shallow lagoons and courses of small rivers that carried sands and fine pebbles. The upper part of the formation is also fluvial with the development of a powerful edaphic horizon of carbonate accumulation.

Concise description of Ain Hanech Formation

- $\mathrm{Mb} \mathrm{P}$ is $10 \mathrm{~m}$ thick starting with unsorted and randomly oriented pebbles contained in mottled pink silt (7.5YR 7/4) and yellow red (5YR 5/6). The upper part (4m) is equally silty but with higher clay content; 
- $\mathrm{Mb} \mathrm{Q}$ is $7 \mathrm{~m}$ thick monotonous series of floodplain sediments with higher clay content (50-60\%), color light brown (7.5YR 5.6/4); fine grained upwards;

- $\mathrm{Mb} \mathrm{R}$ is $3.5 \mathrm{~m}$ thick, the base consists of light brown (7.5YR) sandy silt and scattered gravels capped by pale brown (10YR 8/2) sandy silt, and then light brown silt (7.5YR 6/3);

- $\mathrm{Mb} \mathrm{S}$ is $4 \mathrm{~m}$ thick of light brown (7.5YR 6/4) silt with sand and small to medium-sized pebbles;

- $\mathrm{Mb} \mathrm{T}$ is $4 \mathrm{~m}$ thick mainly silty light brown (7.5 YR 6/4) or pink (7.5YR 7/4) rich in nodular $\mathrm{CaCo} 3$ concretions towards its top $2 \mathrm{~m}$ likely the result of carbonate migration from the overlying $\mathrm{Mb} \mathrm{U}$;

- $\mathrm{Mb} \mathrm{U}$ is $0.75-0.80 \mathrm{~m}$ thick composed of detrital facies of sands and gravels of fluvial origins indurated by carbonates (up to $80 \%$ ).

\section{S3: Sedimentary context of Ain Boucherit archaeological levels (Figure S6) (SA)}

In order to determine the size and origin of the sediments burying the Ain Boucherit archaeological remains, a sedimentological analysis is undertaken. Unconsolidated sediments were sampled from deposits encasing fossil bones and stone tools at AB-Lw ("tree" locus) and at AB-Up. The raw samples were dried beforehand at a temperature of $40{ }^{\circ} \mathrm{C}$ before undergoing a quartering, then separated, by sieving with water, from its coarse elements and retaining only those elements $<2$ $\mathrm{mm}$ (coarse and fine sands, silts and clays). The Malvern Mastersizer 2000 diffraction and diffusion laser granulometer was used. The particle size distribution of the samples was performed using the Gradistat software (55) and the parameters were defined using formulas of Folk and Ward (56). The interpretation of the results is proposed based on data from (55-57).

The results show the frequency of each of the size classes of the particles forming the sedimentary matrices of both archaeological deposits (Fig. S6). The sedimentary matrix (sample AB2) of ABLw consists mainly of silt (83\%), fine sand (14\%), clay (2\%), and coarse sand (1\%). The AB-Up archaeological materials are associated with the gravel deposits (sample AB22) and the muddy deposit (samples AB20 and AB21) but the bulk of the remains are accumulated in the latter. The gravel deposit is formed primarily of sand $(87 \%)$ versus silt $(18 \%)$. However, the matrix of the muddy layer consists of primarily silt (78\%) and clay (18\%). The sedimentological analysis suggests that AB-Lw and AB-Up Oldowan stone tools and cutmarked bones were buried primarily in silty sediments. Silty sediments characterize floodplains, which are known actualistically to be deposited at lower velocity regime.

\section{S4: Biochronology (Figures S7 and S8; Tables S8 and S9) (JvdM; KB)}

Some suid remains from $\mathrm{AB}-\mathrm{Lw}(\mathrm{Mb} \mathrm{P})$ were assigned to Kolpochoerus phacochoeroides or a similar form $(13,58)$ or to the "Metridiochoerus-Phacochoerus group" (59). The narrow symphysial area, low crown and simple molar morphology (Fig. S7: 3) are more in favour of a primitive species of Kolpochoerus, but the material is insufficient to attribute it to a species. The cheek teeth (18) and canine (58) of Kolpochoerus from Ain Hanech and El Kherba are morphologically and metrically similar to $K$. heseloni (=K. limnetes [see 17]). The transition of $K$. heseloni/limnetes to K. olduvaiensis was around $1.7 \mathrm{Ma}(19,20)$. The lack of enamel on the upper canines at Ahl al Oughlam was used to suggest that a separate lineage of Kolpochoerus existed in North Africa $(58,59)$ and it has been suggested that this material belongs to Metridiochoerus $(60)$. 
The Kolpochoerus from Ain Hanech and from AB-Up (Mb R) has canines with clear enamel bands as in East Africa (Fig. S7: 2, 6: 11).

The first appearance of Equus in Africa is often considered to be at $2.32 \mathrm{Ma}$ at the base of $\mathrm{Mb} \mathrm{G}$ of the Shungura Fm (61). However, the genus was identified from Zone C (62), which corresponds to the Lower Burgi Mb of the Koobi Fora Fm. This would imply that Equus arrived around 2.6 $\mathrm{Ma}$ as it did in Eurasia. Figure S8 displays the temporal ranges of the Equus species according to Bernor et al (61). The phylogenetic relationships between these species are not clear. The species Equus numidicus and E. tabeti are mainly known from Algerian localities, though there are suggestions that these or similar species lived in East Africa $(62,63)$. Their most remarkable feature is their gracile metapodials. This is seen in Fig. S8, where these species have red symbols and the robust species have blue or black symbols. East African gracile equids are indicated with orange symbols. There is no gracile species after 1.2 Ma. This precludes a correlation of Ain Hanech and El Kherba to chron C1r.1r and supports a correlation to early chron C1r.3r. This also supports a correlation of $\mathrm{AB}-\mathrm{Lw}(\mathrm{Mb} \mathrm{P})$ to chron $\mathrm{C} 1 \mathrm{r}$.

\section{S5: Ain Boucherit stone tool assemblages (Figures S9-S14; Table S10) (MS; ZH; SS)}

The stone tool assemblages excavated at Ain Boucherit total 17 and 236 specimens (excluding small debitage $<2 \mathrm{~cm}$ of maximum dimension), respectively for AB-Lw (lower archaeological level) and for AB-Up (upper archaeological level) (Table S10). The AB-Lw consists currently of a small assemblage as it emanates from limited trench excavations carried out in three locations within the fossil-bearing stratum that extends north-south along the Ain Boucherit hill, including the southern spur, the northern spur, and the "tree locus". Based on altimetric, stratigraphic, paleontological and taphonomic evidence, the excavated material in each location belongs to the same layer (Fig. S9). This same fossil-bearing stratum previously yielded fossil specimens assigned to the Ain Boucherit "Lower Villafranchian level" fauna $(12,13)$. The locations of the northern spur and southern spur have a great potential for future excavations of AB-Lw. Large scale horizontal excavations at these two locations are currently not possible due to the steepwalled exposures and $\sim 20 \mathrm{~m}$ sediment of overburden. The excavations in this deposit are achievable only after entirely excavating the overlying AB-Up deposit and removing at least $\sim 8 \mathrm{~m}$ thick of sterile sediments separating the two archaeological layers. The AB-Lw stone tools and associated cutmarked bones with invertebrate and vertebrate fossils are encased in fine-grained sediments consisting primarily of silt and clay (Fig. S6; see also sedimentary context in SM [S3]). The lithic artefacts are fresh, and the bones display well-preserved surfaces suggesting a rapid burial.

The AB-Lw and AB-Up lithic assemblages are made of limestone and flint. According to the geological map of the region, the limestone includes several varieties formed in the Cretaceous. Although the flint displays homogeneous textural patterns, it incorporates a variety of colors, but the black flint is the most predominant. Our field survey for raw materials reveals that the original sources of these two types of rock are the rocky hills flanking the Beni Fouda sedimentary basin. Pieces of limestone and flint broke up over time and have been transported by streams draining into the alluvial plain. They became cobbles and pebbles, mostly characterized by a polyhedral shape due to their short transport and were deposited in nearby river beds and stream courses. 
Nowadays, limestone and flint cobbles are present in several fossil conglomerates throughout the research area, the densest of which occur at the base of Ain Hanech Formation a few meters below AB-Lw. Other gravel deposits are located stratigraphically below AB-Up (Fig. 1). A metric study of a sample of gravels, collected from dismantled parts of these conglomerates, using Zingg's system (71) shows the predominant clast shape available is polyhedral (mean of B/L and TH/B ratios $=0.73$ and 0.75 for limestone and flint cobbles, respectively) (Fig. S10). These types of cobbles were readily accessible to Oldowan knappers for manufacturing Ain Boucherit artefacts, and their shapes likely influenced core flaking strategies and the resulting typological forms. As a matter of fact, the Ain Boucherit cores incorporate primarily polyhedrons and subspheroids (half of the cores) suggesting the influence of the polyhedral clast shape predominantly available to the knappers.

The AB-Lw assemblage includes 7 cores, 9 flakes and a single retouched piece (Fig. 3, Fig. S11). The cores (mean dimensions: 85.7 x 67.0 × $55.8 \mathrm{~mm}, 502.8 \mathrm{~g}$ ) are primarily polyhedral and irregularly flaked with variable scar counts ranging between 2-8 scars and one core having up to 29 scars. The Oldowan-makers flaked most cores by rotating them $90^{\circ}$ (adjacent striking platforms) and/or $180^{\circ}$ (opposed striking platforms) probably in an attempt to locate suitable percussion angles to knock off good quality flakes. They flaked two cores using one single striking platform, including one onto one face with hinge and step flake terminations, and the other with flaking extending around the platform perimeter. They flaked one core so extensively to the extent that it is hard to identify the striking platforms. Half of associated flakes have cortical dorsal faces and butts. The retouched piece is a notched scraper made of flint measuring $25.0 \times 23.0 \times 10.0$ $\mathrm{mm}$.

The AB-Up stone assemblage is richer as it derives from a large-scale horizontal excavation. Based on a number of indications, the bulk of the archaeological material is in primary geological context, including fine-grained sedimentary matrix; high representation of debitage ${ }^{1}$ and lighter elements $<2 \mathrm{~cm}$ of maximum dimension (Fig. S12: 1, 2), vertical concentration of the remains; absence of: 1) preferred orientation, 2) high inclination, and 3) noticeable size sorting of artefacts (Fig. S13: 1-3). Yet, slight rearrangement of remains cannot be ruled out. The lithic assemblage totals 834 (including small debitage $<2 \mathrm{~cm}$ of maximum dimension) incorporating the following categories: $121(14.5 \%)$ cores, $65(7.79 \%)$ flakes, $47(5.63 \%)$ fragments, and $3(0.35 \%)$ retouched pieces (Table S10). Most of the cores were made on limestone than on flint (95.8\% vs $4.13 \%)$. The cores (mean measurements 95.7 × 80.3 x $65.5 \mathrm{~mm}, 659.8 \mathrm{~g}$ ) were variably flaked including light $(37.19 \%)$, moderate $(41.32 \%)$, and heavy $(21.48 \%)$; with $50 \%$ of the cores still retaining cortex. Single (49.58\%) and multiple striking platforms (2-3 platforms $45.45 \%$ ) were equally exploited. Based on M. Leakey's typological system (72), the cores include unifacial and bifacial choppers (16.94\% and $8.05 \%$, respectively), polyhedron (23.05\%), subspheroids (1.69\%), spheroids $(0.84 \%)$, and split cobbles $(0.42 \%)$. Most of the flakes (mean dimensions: $40.4,27.6,11.6 \mathrm{~mm})$ were made on limestone $(58.46 \%)$ whereas the remaining were made on flint $(41.53 \%)$. In terms of cortex, nearly $37 \%$ have cortical dorsal faces whereas $67.69 \%$ have cortical platforms. About

\footnotetext{
${ }^{1}$ Debitage means here flakes and fragments resulting from the flaking of cores including lighter elements $<2 \mathrm{~cm}$ of maximum dimension.
} 
$43 \%$ of the flake dorsal faces show scars that were removed using unidirectional flaking. Made of flint, the three retouched pieces (mean dimensions: 26.9 × $21.9 \times 8.4 \mathrm{~mm}$ ) include two simple scrapers and one notched scraper.

Overall, the Ain Boucherit lithic assemblages (Fig. 3, Fig. S11, Table S10) belong to the early Oldowan but show some subtle differences with the stone assemblages from East Africa dated to 2.6-2.0 Ma (1, 3-6). The earliest East African sites comprise primarily of unifacial cores (e.g. EG10 and EG12) (1) and bifacial cores (e.g. OGS6 and OGS7 [2], Haddar [5]), whereas the Ain Boucherit assemblages incorporate rather more polyhedral forms and to a lesser extent unifacial and bifacial core forms likely due to the predominance of polyhedral clast shape available to Ain Boucherit knappers. Thus, the rarity of polyhedral forms at these East African sites is difficult to explain but it is probably due to raw material variability. Nevertheless, the Ain Boucherit cores share basic typological and technological characteristics with these early Oldowan assemblages, despite differences in raw materials and general core types. As a matter of fact, a brief comparison ${ }^{2}$ between the Gona and Ain Boucherit cores reveals the presence among Gona specimens of polyhedral forms dated to 2.6 Ma. However, these polyhedral forms became more common at Gona 2.2 Ma, e.g. OGN-3 (Fig. S14), a main characteristic technological feature also shared at Ain Boucherit. As shown in Fig. S14, there are striking similarities between the Gona OGN-3 and the Ain Boucherit polyhedral cores both in terms of technological patterns and overall shapes. Specimens from both sites show the pattern of using a single non-cortical striking platform and the rotation of the cores during knapping.

Compared to the relatively younger Oldowan sites of Ain Hanech and El Kherba dated to 1.78 $\mathrm{Ma}$, the Ain Boucherit Oldowan assemblages are strikingly poor in retouched pieces. This trait has also been observed in the East African Oldowan assemblages that are 2.0 Ma and older, e.g. Gona (1), Lokalalei (73), Omo (4), and Hadar (5). The retouched elements in the Oldowan become abundant by $1.8 \mathrm{Ma}$ and later, e.g. Olduvai (72), Ain Hanech and El Kherba (29), and NY18 at Nyabusosi (74). In this respect, the technological progression of the Ain Boucherit Oldowan assemblages are more consistent with the early Oldowan assemblages of Eastern Africa.

\footnotetext{
${ }^{2}$ A comparative study between Ain Boucherit and Gona lithic assemblages is being carried out in collaboration with Dr. Sileshi Semaw in the framework of a comprehensive study of Oldowan variability in East and North Africa, which will be published in the near future.
} 

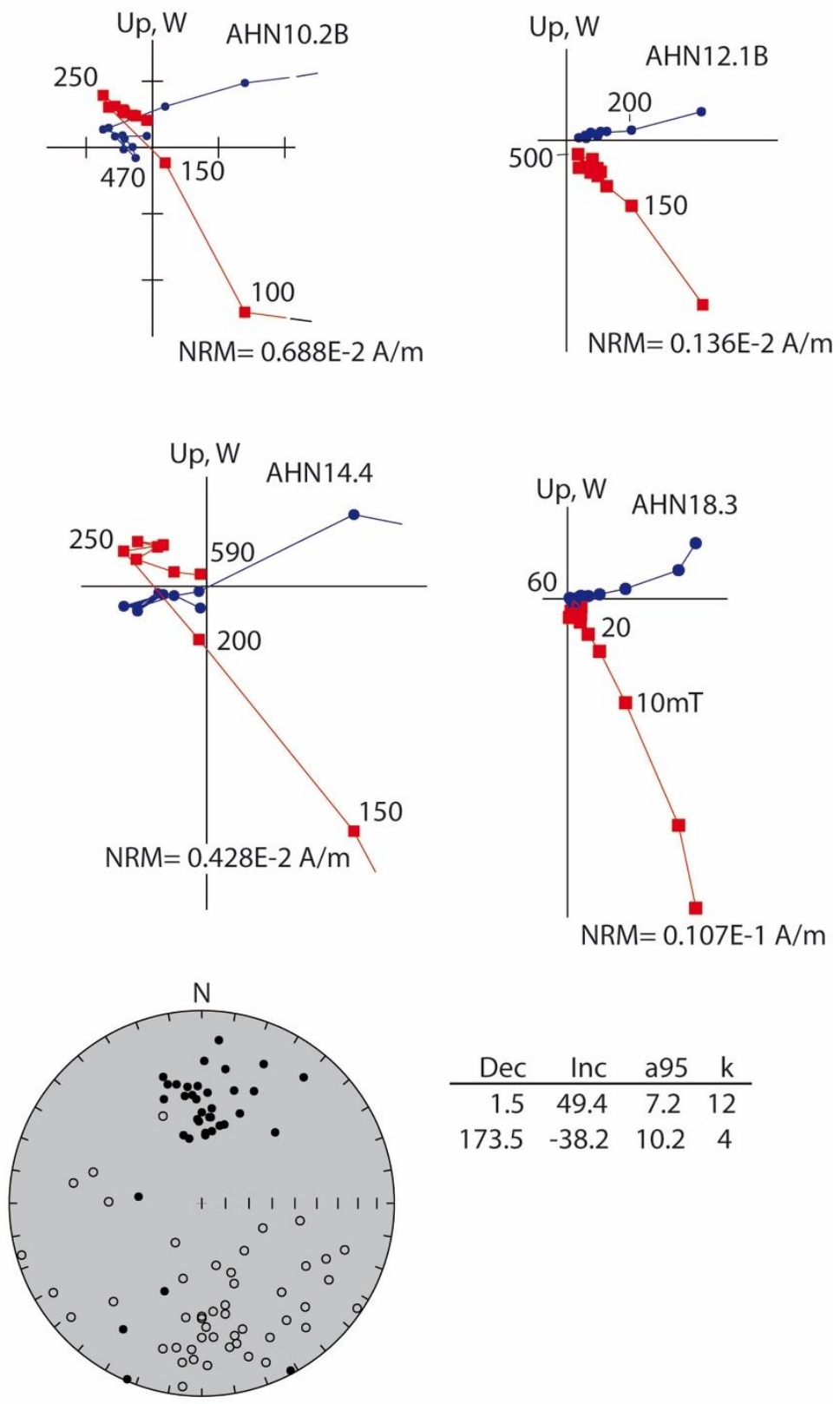

\begin{tabular}{rrcc} 
Dec & Inc & a95 & k \\
\hline 1.5 & 49.4 & 7.2 & 12 \\
173.5 & -38.2 & 10.2 & 4
\end{tabular}

Fig. S1. Examples of progressive alternating field demagnetization displayed by vector end point diagrams (31) of representative samples (top). Each data point represents the Natural Remanent Magnetization (NRM) end vector for individual demagnetization steps projected onto the horizontal (blue dots) and vertical (red squares) plane. Initial value of NRM (A/m) is also shown. Temperature steps are shown in degrees Celsius for specimens AHN10.2B, AHN12.1B, AHN14.4, and alternating field peak values in miliTesla for specimen AHN18.3. Diagrams are shown in geographic coordinates. (bottom) lower hemisphere stereographic projection of the Characteristic Remanent Magnetization (ChRM) directions. Dots (circles) denote vectors projected onto the lower (upper) hemisphere. Mean directions for both normal and reverse directions are shown right of the stereonet. 


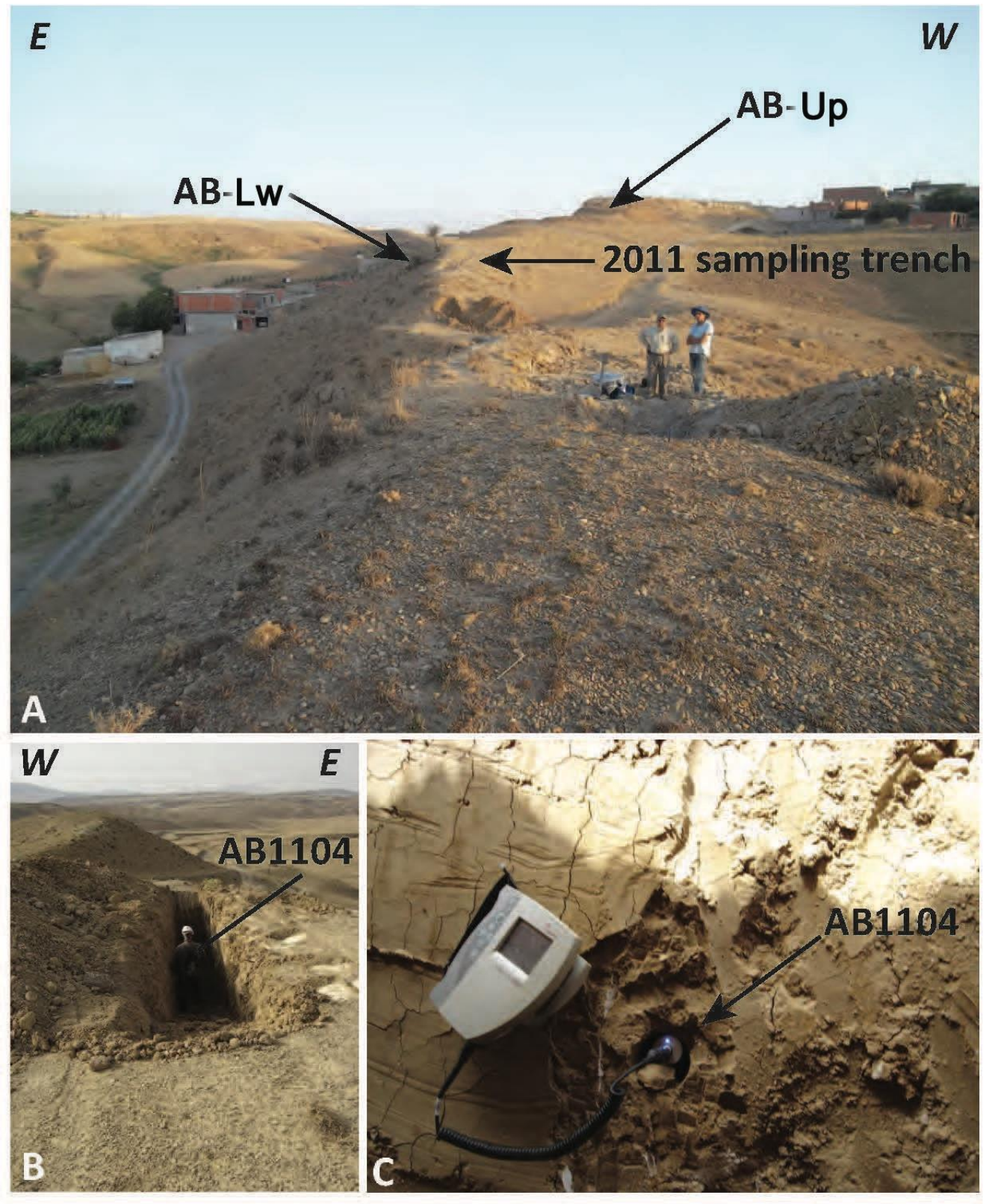

Fig. S2. Position of the ESR sample AB1104. (A): Overview of the Ain Boucherit area. The picture was taken in 2016, so the original 2011 trench is no longer visible. (B) Sampling trench where ESR and palaeomagnetic samples have been collected. (C) in situ measurement of radioactivity with a NaI probe. 

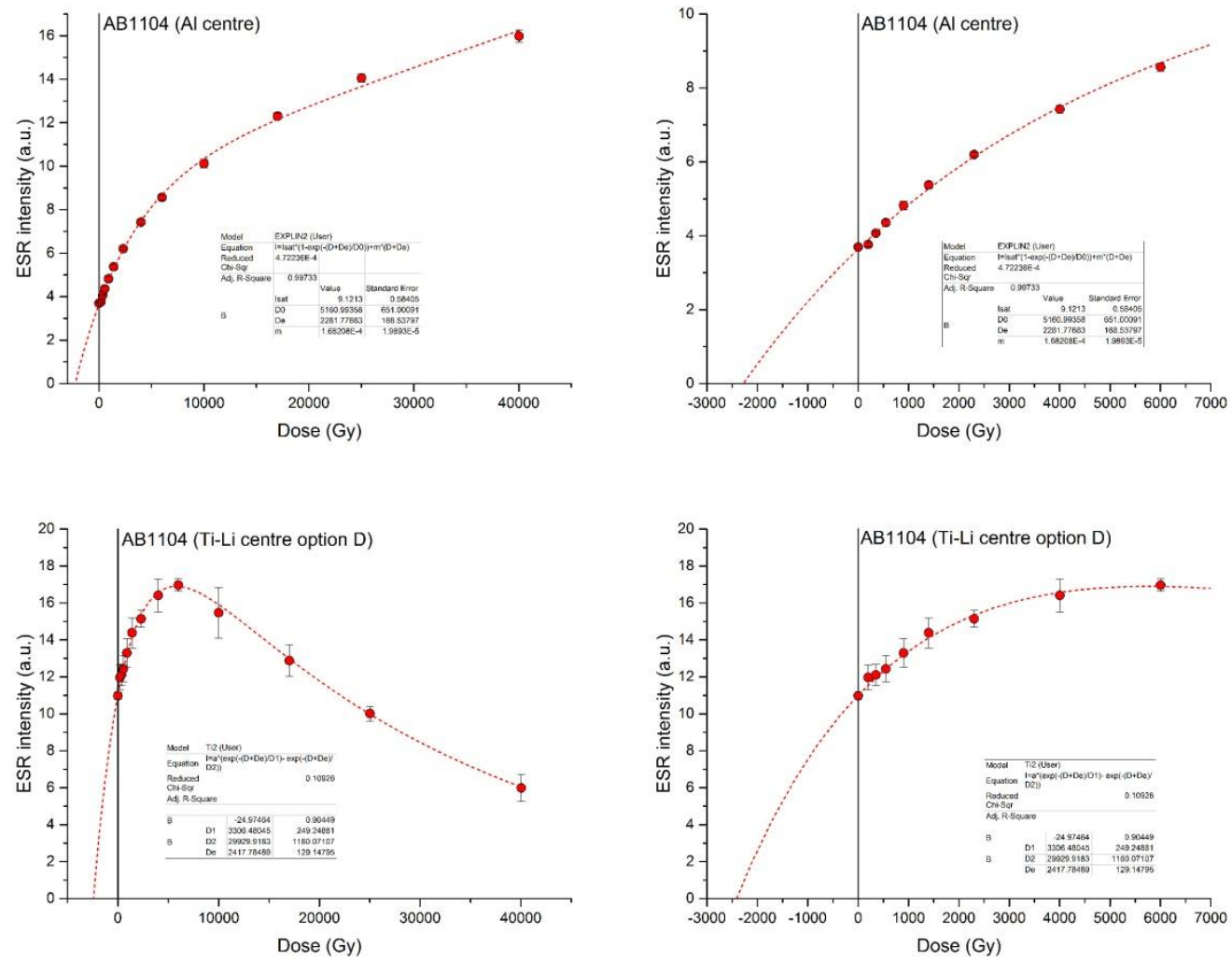

Fig. S3. ESR dose response curves (DRCs) obtained for samples AB1104. Top: Al centre; Bottom: Ti-Li centre (option D); Left: full dose range; Right: zoom on the first part of the DRC up to 7 kGy. 


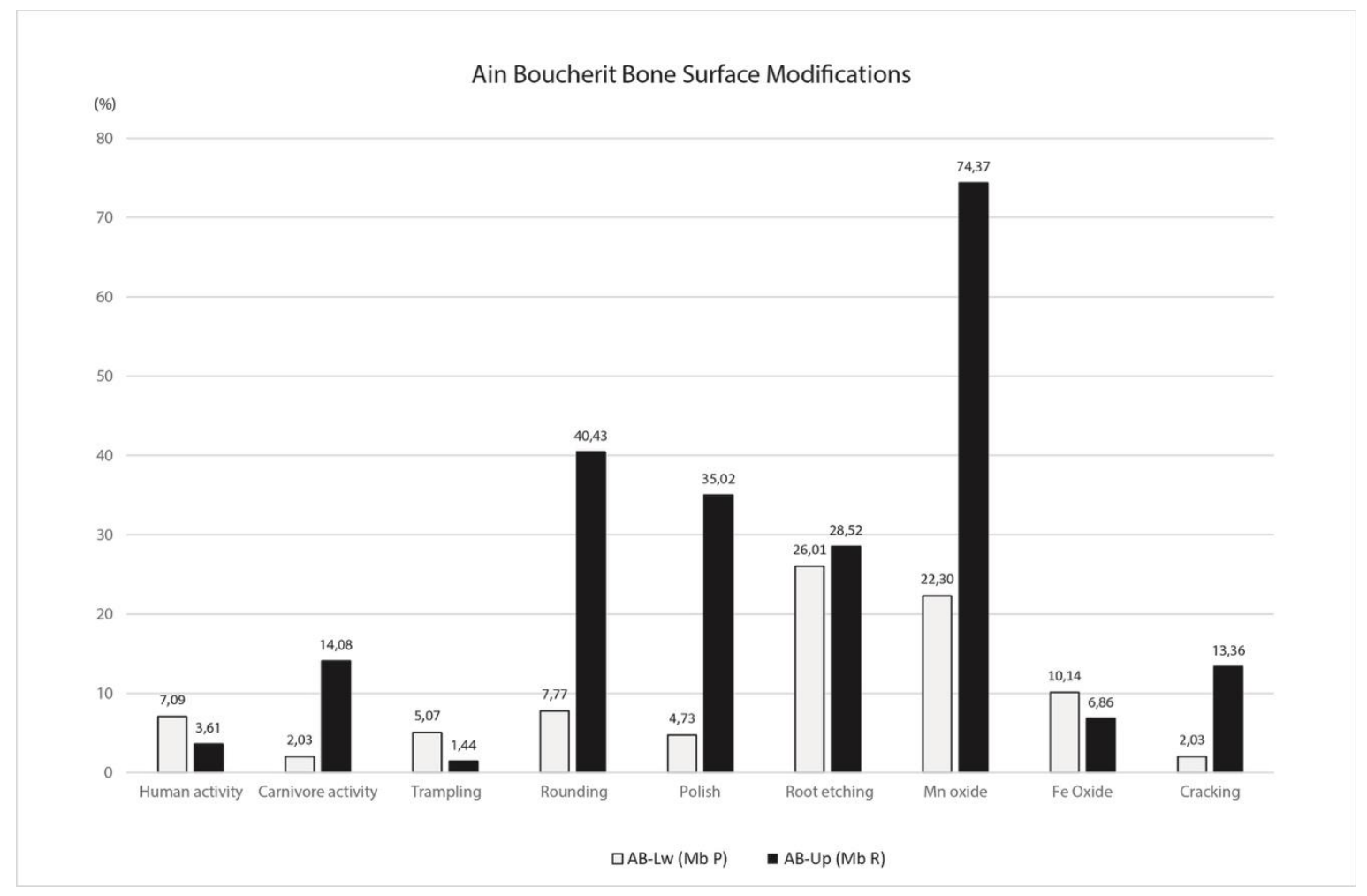

Fig. S4. Bone surface modifications recognized in Ain Boucherit fossil assemblages of lower archaeological level (AB-Lw) and upper archaeological level (AB-Up). 


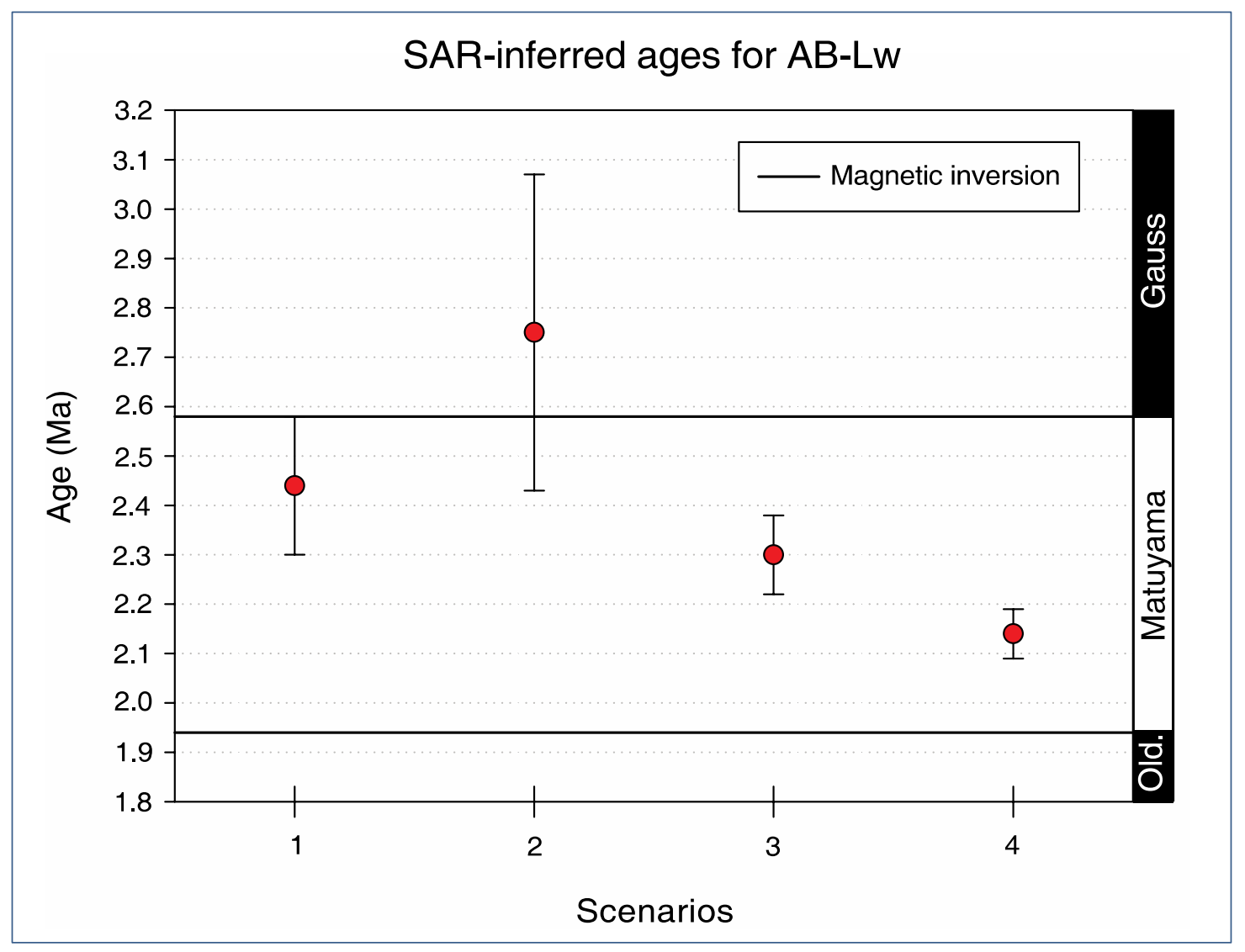

Fig. S5. SAR-inferred ages for AB-Lw, as described in supplementary text S1. Scenario: (1) our most reasonable estimate (depth of the G-M boundary $=22 \mathrm{~m}$ and SAR derived from C2r (postGauss pre-Olduvai) chron (1.62 $\pm 0.35 \mathrm{~cm} / \mathrm{ka})$; see Fig. 2); (2) considering G-M boundary $4 \mathrm{~m}$ above than in scenario 1 (depth $=18 \mathrm{~m}$ ) and SAR derived from C2r (post-Gauss pre-Olduvai) chron; (3) considering G-M boundary $4 \mathrm{~m}$ below than in scenario 1 (depth $=26 \mathrm{~m}$ ) and SAR derived from C2r (post-Gauss pre-Olduvai) chron; (4) considering G-M boundary at depth $=22 \mathrm{~m}$ and SAR derived from the Olduvai subchron $(4.07 \pm 0.85 \mathrm{~cm} / \mathrm{ka})$. 

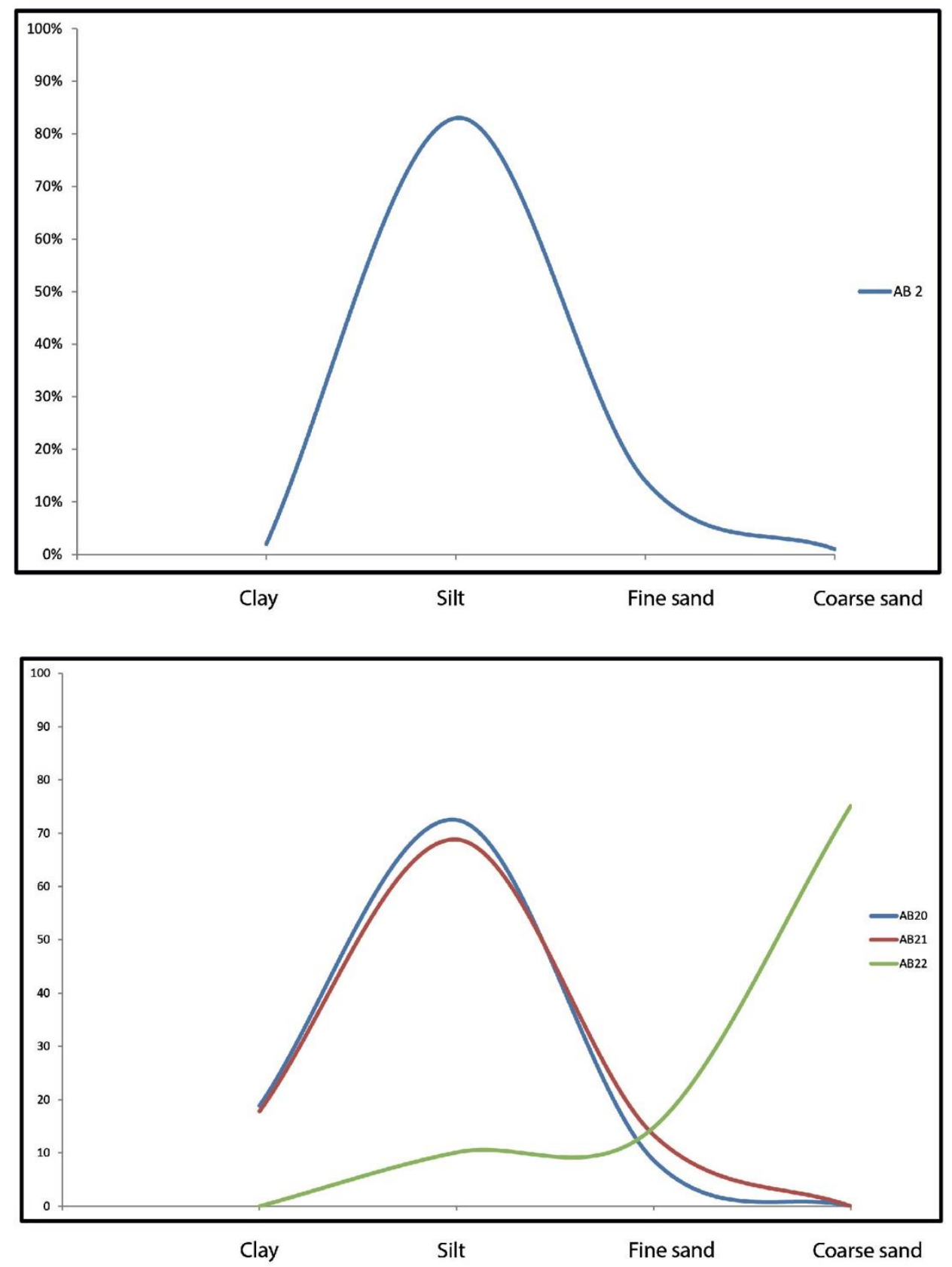

Fig. S6. Sediment grain size of the Ain Boucherit lower archaeological level (AB-Lw) (top) and upper level (AB-Up) (bottom). In AB-Up, the bulk of the archaeological remains are encased in fine-grained sediments (samples AB20 \& AB21), and a few specimens are in coarse sediments (sample AB22). 


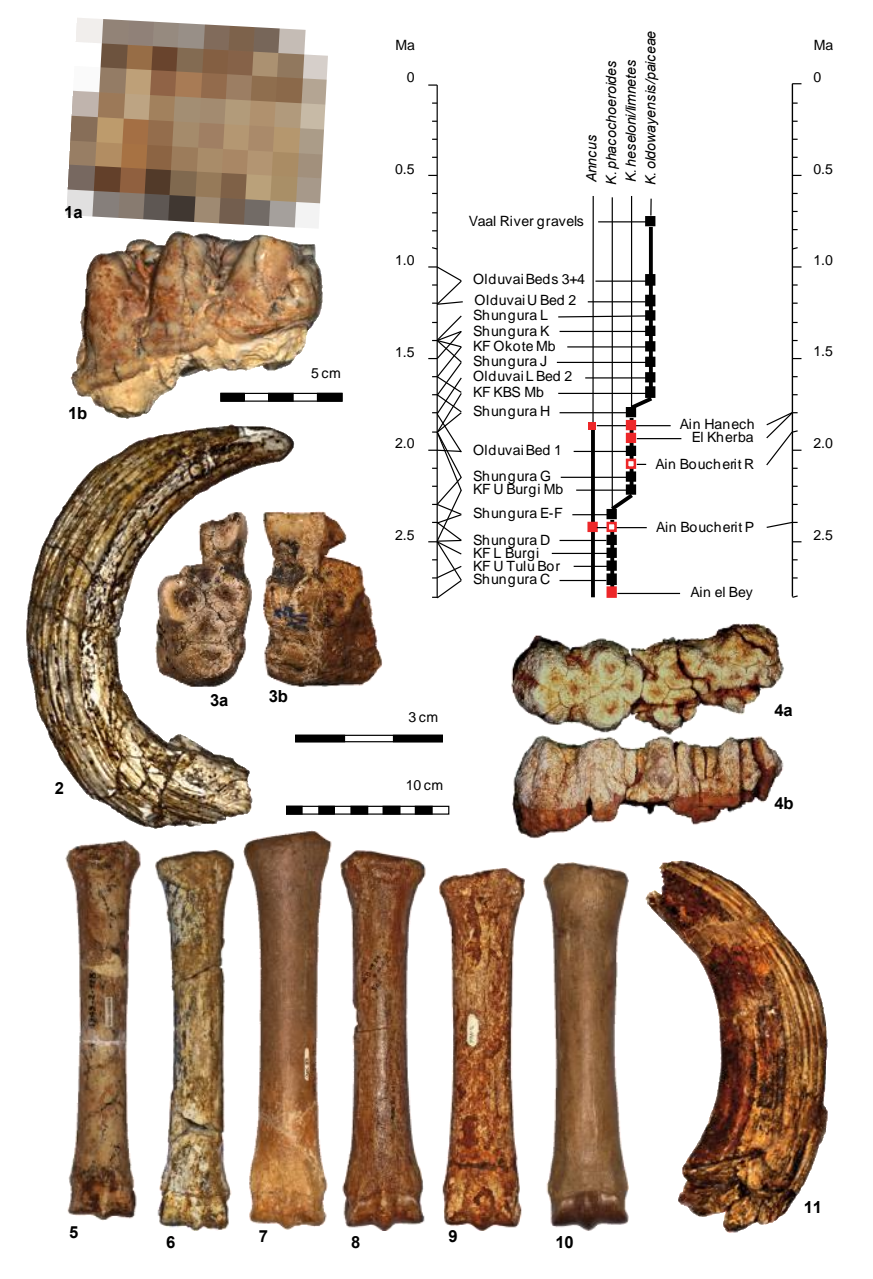

Fig. S7. Fossils from AB-Lw (Mb P) (1, 3, 7), AB-Up (Mb R) (2), Ain Hanech (4, 5, 9, 11), El Kherba (6), and Olduvai (8, 10). 1) AH98-112: Anterior lower molar fragment of Anancus: a) occlusal and b) lingual views; 2) AB16-F23-3: Left upper male canine, ventral view, showing the lingual enamel band; 3) MNHN 1949-2-371: Left M3 of Suidae indet. (Kolpochoerus?): a) occlusal, and b) lingual views; 4) AH99-E2-EB5-125: Left M3 of Kolpochoerus heseloni: a) occlusal and b) lingual views; 5) MNHN 1949-2-128 (= HAN19): Left metacarpal of Equus tabeti, anterior view; 6) BMA KH06-H30-208: Left metacarpal of Equus tabeti, anterior view; 7) MNHN 1953-22-115 (=BOC 83): Left metacarpal of Equus numidicus, anterior view; 8) NBC OLD1959, NWKII 566: Left metacarpal of a gracile Equus, anterior view; 9) MNHN 1948-1-65 (=HAN4): Left metacarpal of a robust Equus, anterior view; 10) NBC HWK-EII57: Right metacarpal of a robust Equus, anterior view; 11) MNHN 1949-2-647: Right upper male canine, ventral view. (BMA = Bardo Museum, Algiers; MNHN = Muséum naional d'Histoire naturelle, Paris; $\mathrm{NBC}=$ Naturalis Biodiversity Center). Figures 1,2 and 11: $5 \mathrm{~cm}$ scale bar. Figures 3 and 4: $3 \mathrm{~cm}$ scale bar. Figures 5-10: $10 \mathrm{~cm}$ scale bar. Temporal distribution of Anancus and the different species of Kolpochoerus. Open squares indicate insecure classification (aff., cf., sp.?). 


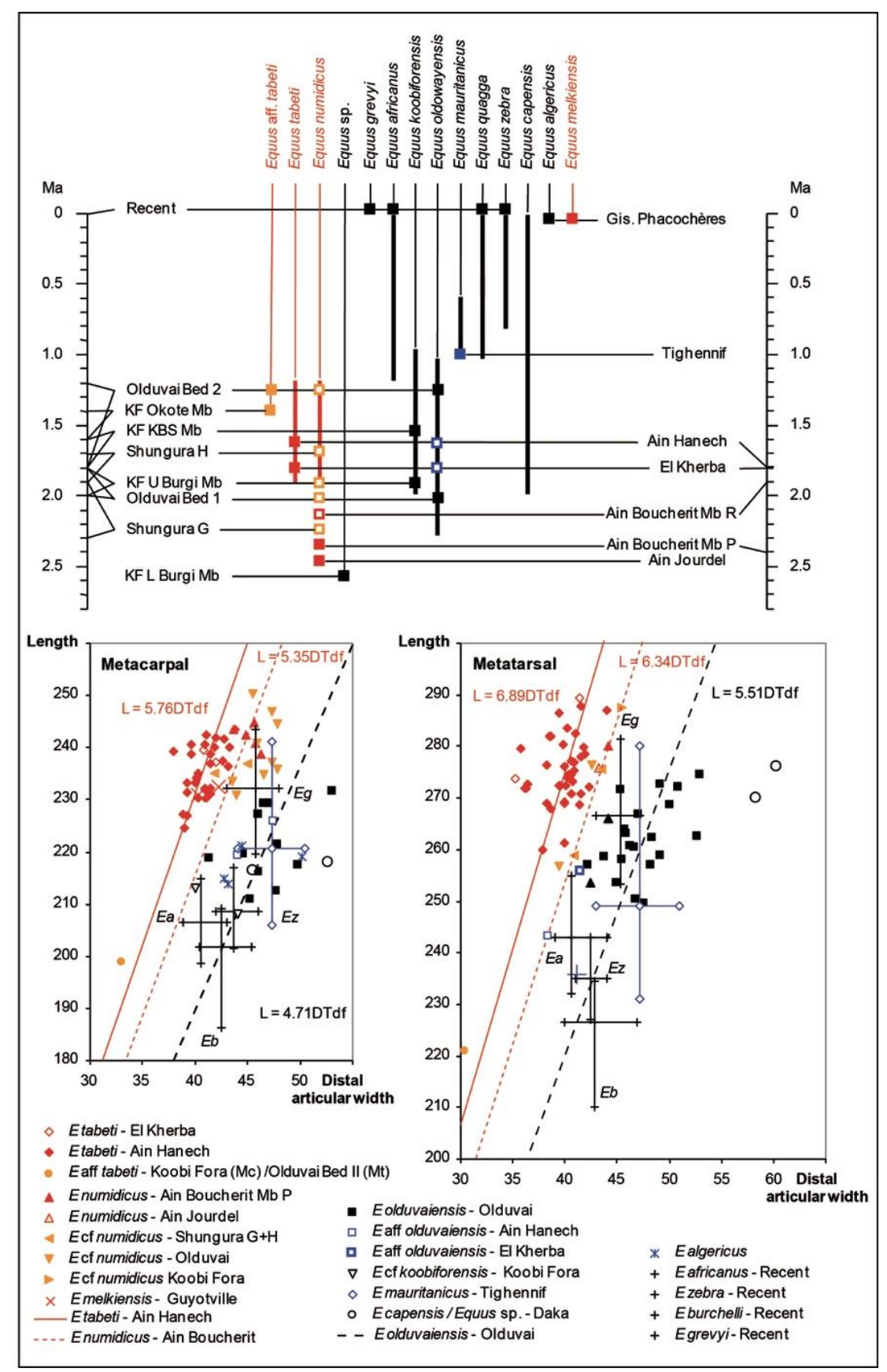

Fig. S8. The last appearance of gracile Equus. Gracile species are indicated with red and orange colors. The temporal ranges of the African species of Equus $(61,62)$ and their presence in selected localities or stratigraphic units (open squares indicate possible presence). Data sources in Table S9. 


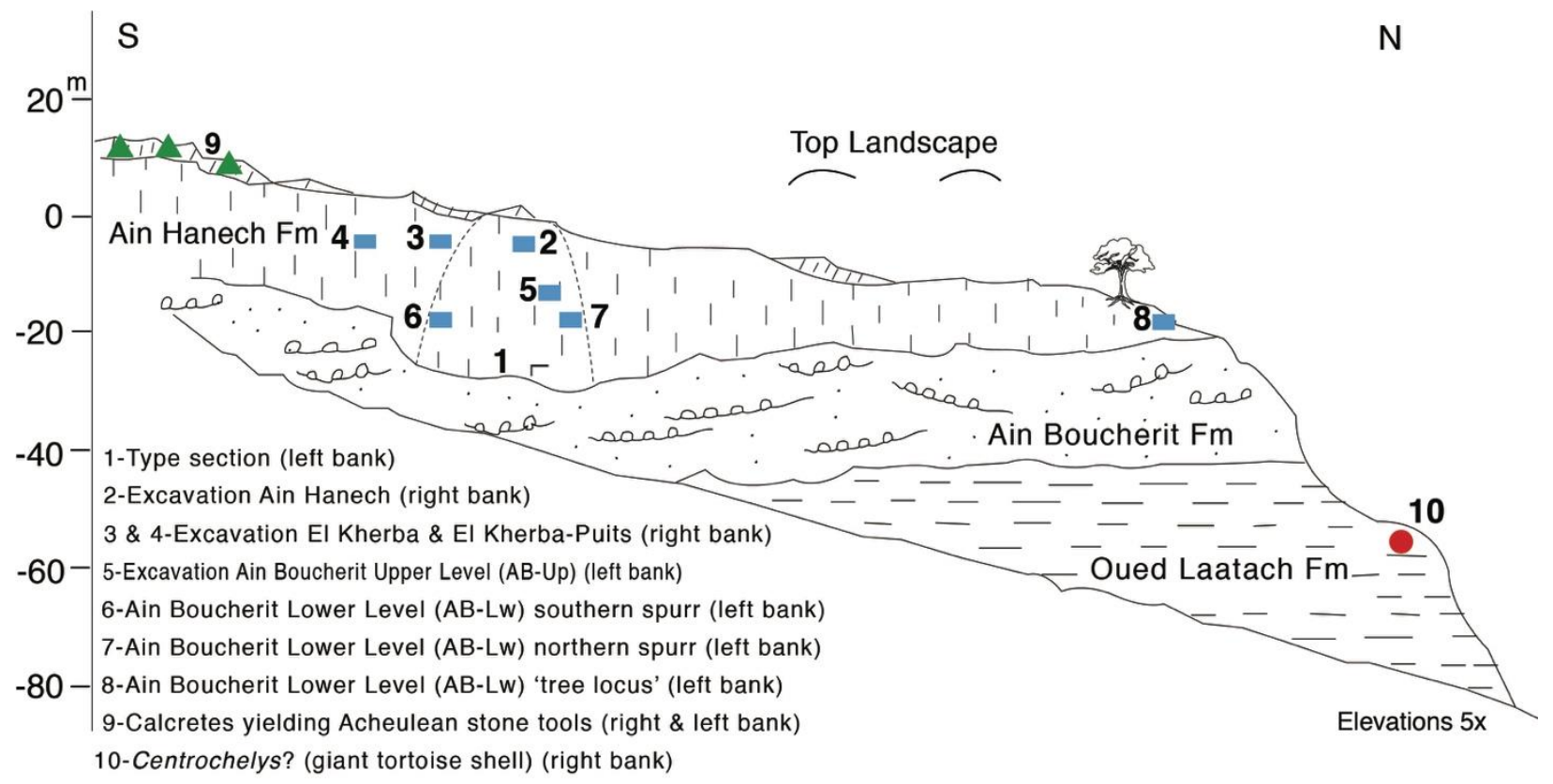

Fig. S9. Stratigraphic profile of Ain Hanech research area showing AB-Lw trenches $(6,7,8)$ positions relative to one another, as well as relative to the older paleontological deposit yielding Centrochelys (10) and to excavations of younger Oldowan horizons of AB-Up (5), Ain Hanech (2), El Kherba (3), and El Kherba-Puits (4). Note that AB-Lw Oldowan stone tools excavated from trenches $(6,7,8)$ belong to the same fossil-bearing stratum that extends north-south along the Ain Boucherit hill. (Stratigraphic profile updated from 29) 


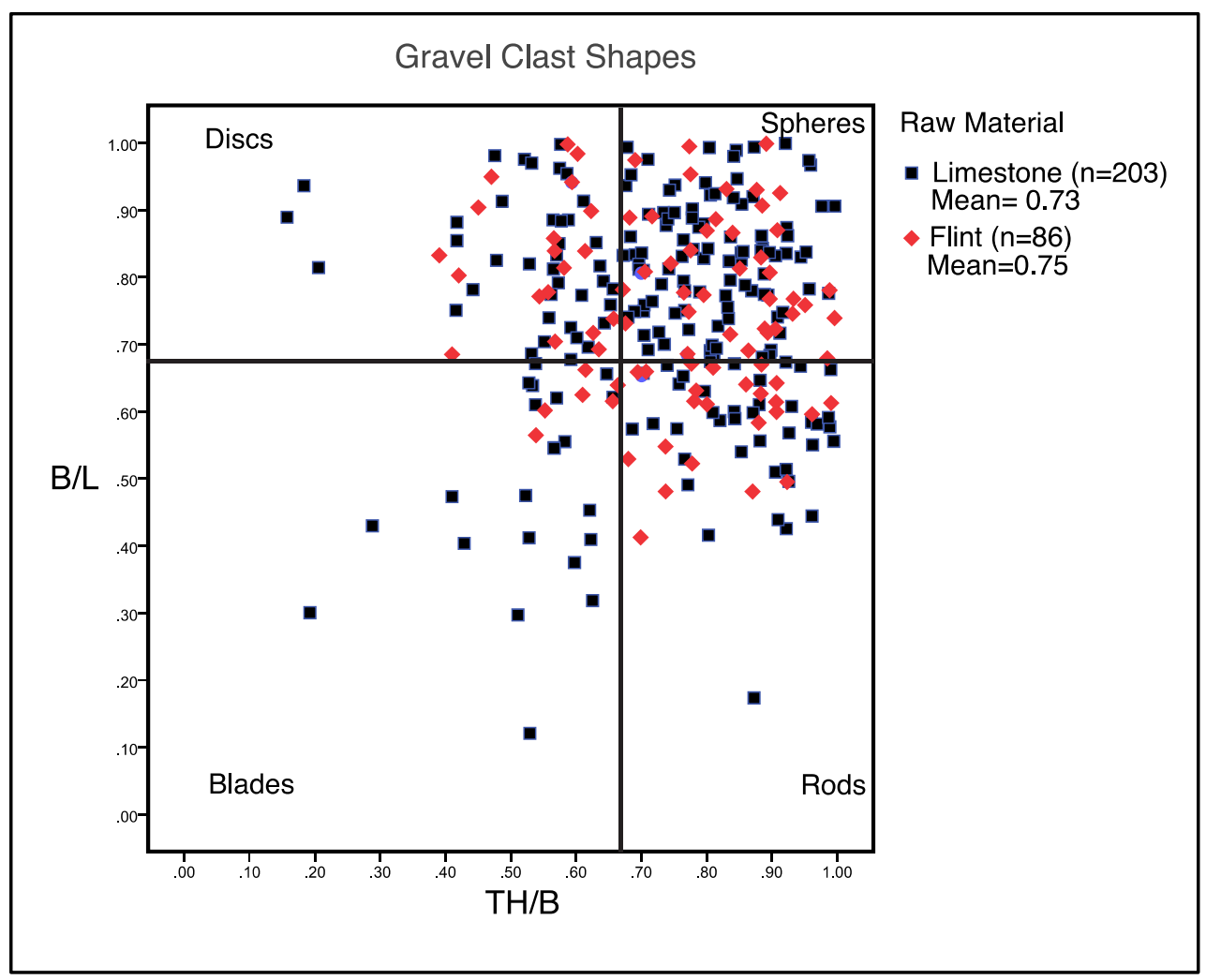

Fig. S10. Gravel clast shapes based on a metric study of a sample cobble from dismantled conglomerates in the Ain Boucherit area using Zingg's system (71). The system separates the gravels into basic shapes by plotting ratios of breadth/length (B/L) and thickness/breadth (TH/B). The means of the plotted ratios situate both limestone and flint cobbles in the polyhedral/spherical area. Likewise, the means of the same ratios (0.79 and 0.83, respectively AB-Lw and AB-Up) situate Ain Boucherit archaeological cores in the same polyhedral/spherical area. 


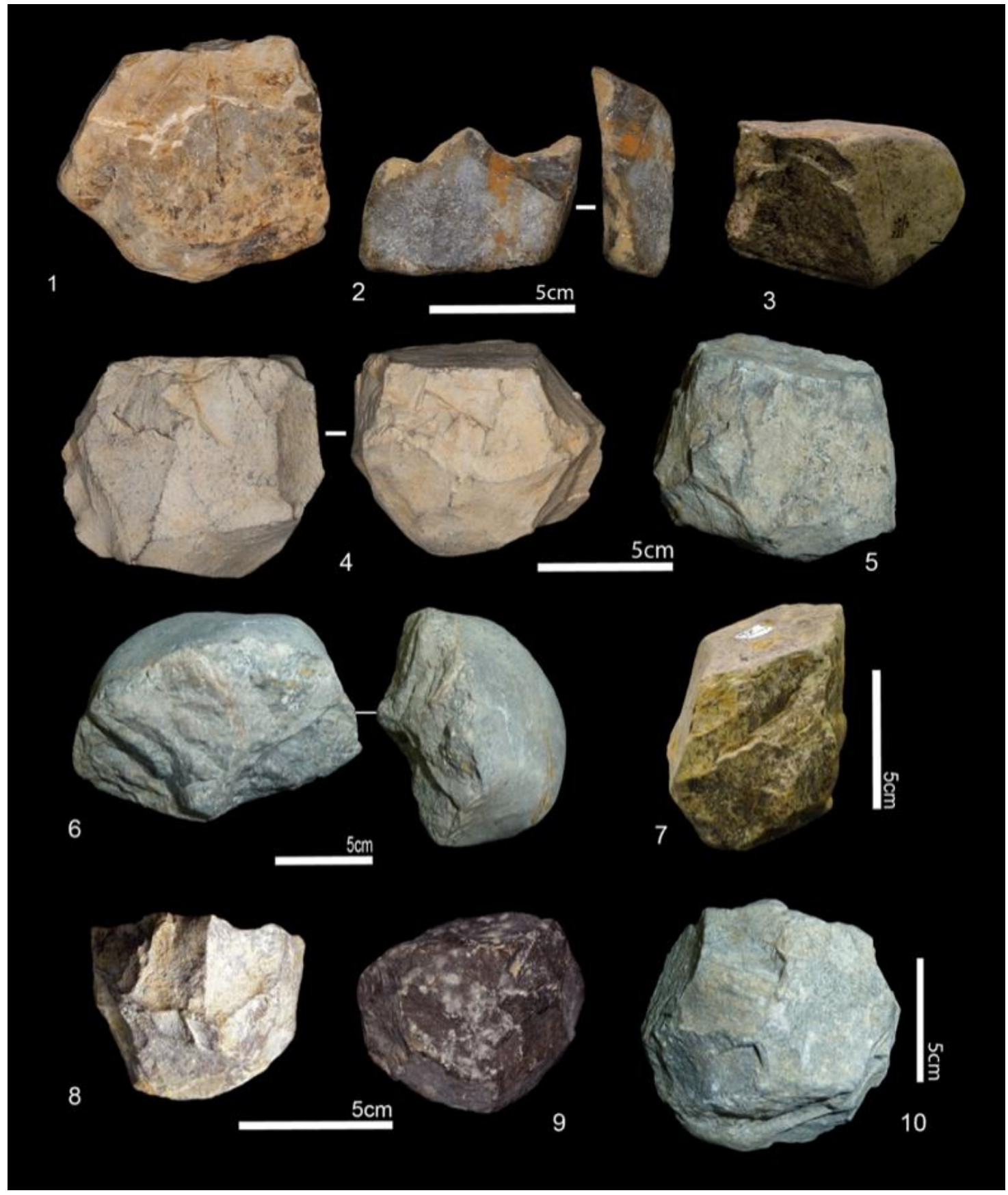

Fig. S11. Oldowan artefacts from AB-Lw (Mb P) (1, 2, 4) and AB-Up (Mb R) (3, 5-10), including various core forms in limestone: unifacial cores $(1,3,6)$; bifacial cores $(2)$; cores showing extended flaking on more than one face $(7,8)$; polyhedral cores $(4,5)$; spheroidal core $(10)$; and polyhedral core used also as hammerstone (9). 

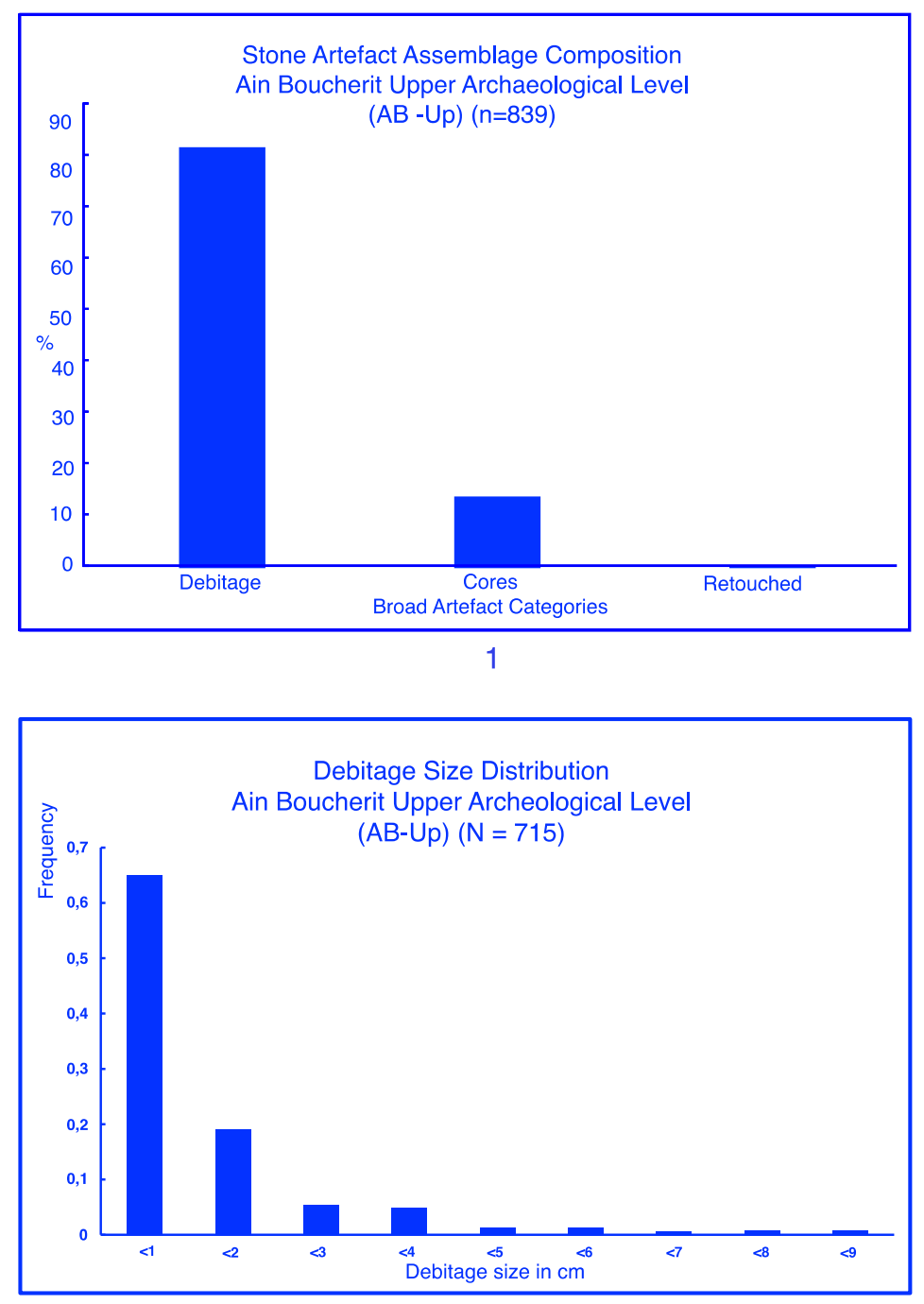

2

Fig. S12. Stone artefact assemblage composition (1) and debitage size distribution (2) of AB-Up. 


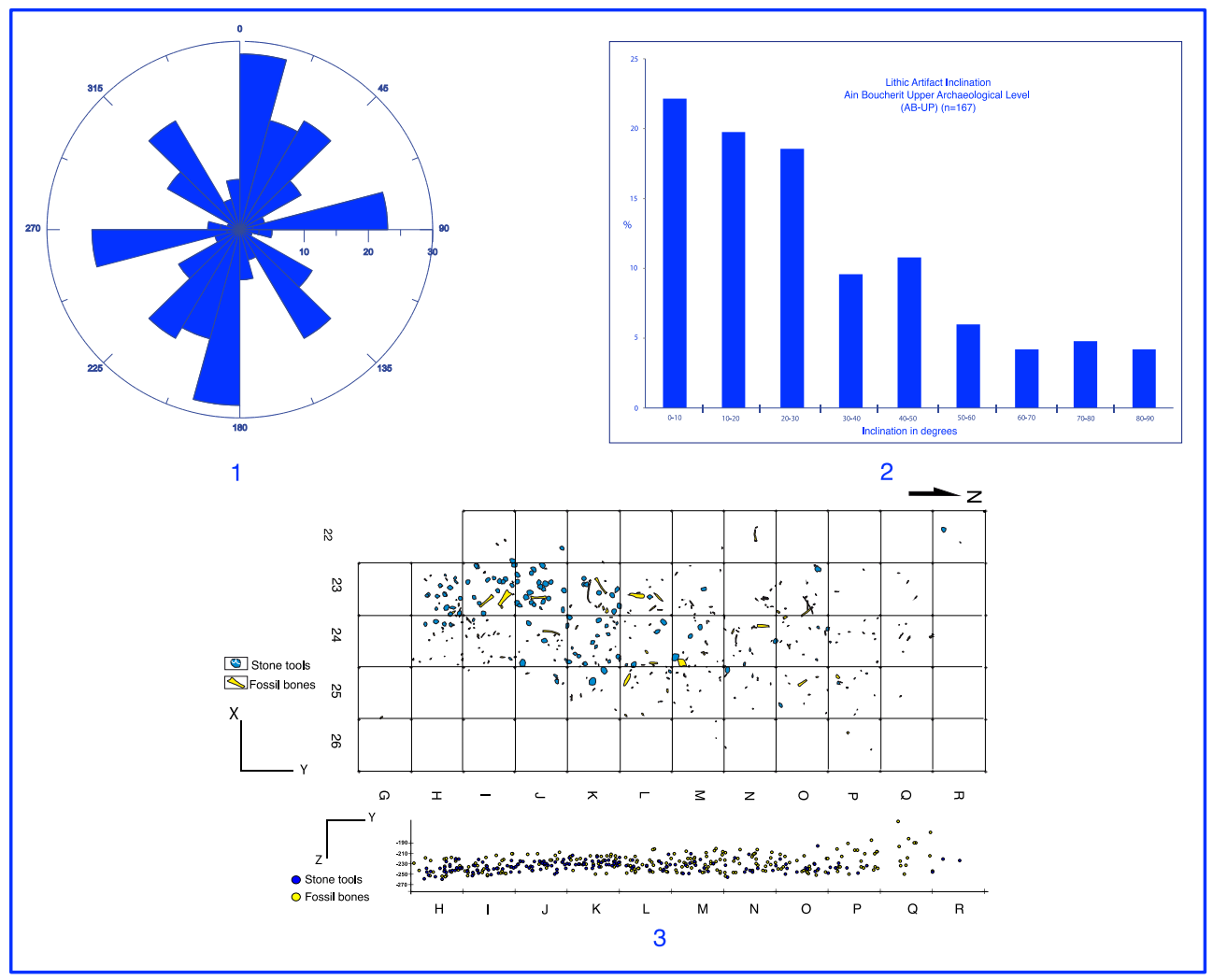

Fig. S13. Patterns of AB-Up lithic artefacts concentration including absence of preferred orientation (1) and high dip of artefacts (2); and horizontal and vertical distribution of fossil bones and stone artefacts occurring densely concentrated within 30-40 cm (3). 


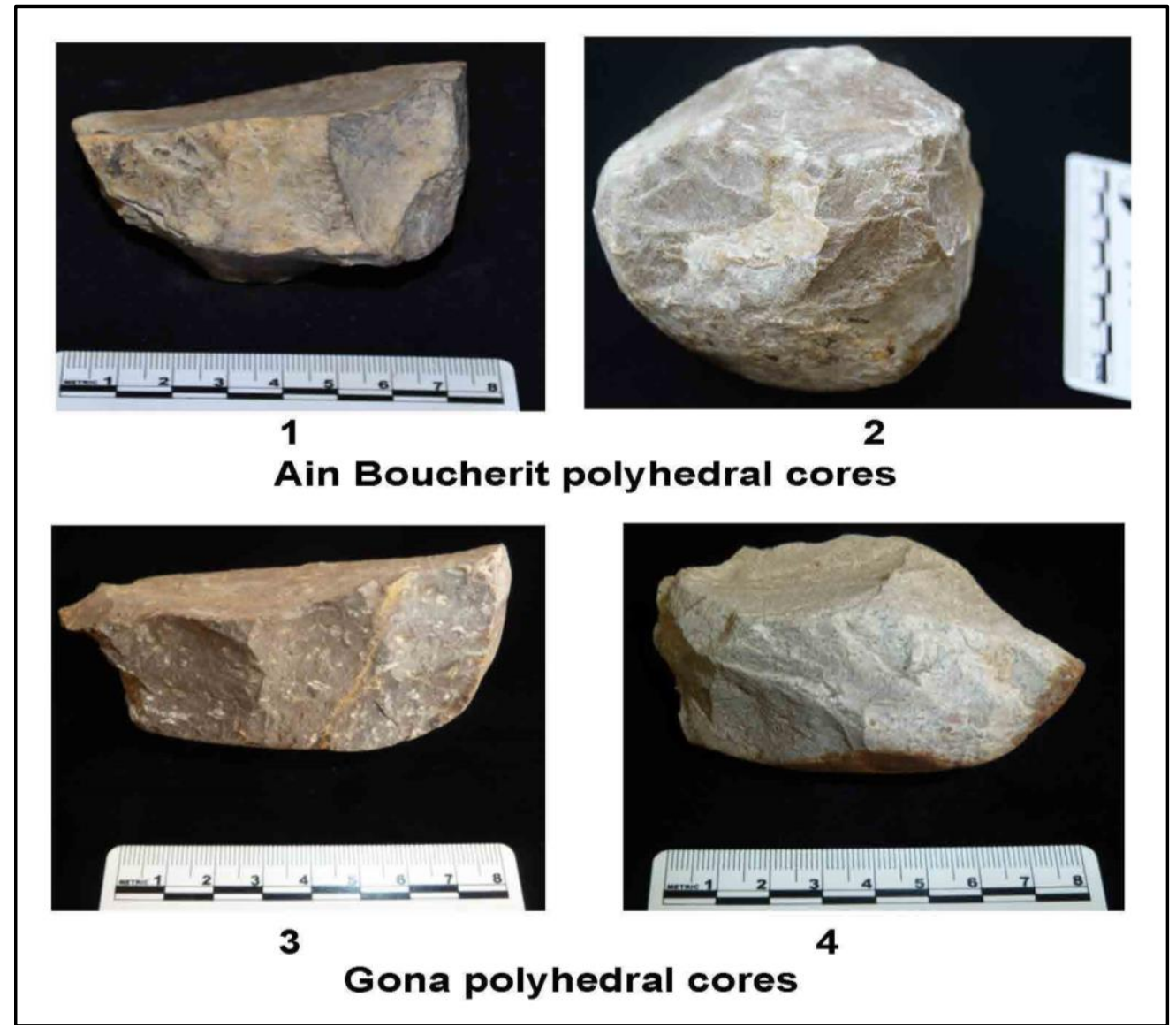

Fig. S14. Examples of technological and shape similarities between the Gona (Ethiopia) and the Ain Boucherit (Algeria) cores showing peripheral flaking patterns, including 1 \& 2: polyhedral cores in limestone from Ain Boucherit (AB-Up); and $3 \& 4$ : polyhedral cores in trachyte (3) and latite (4) from Gona OGN-3. These observations denote some of the preliminary results of an underway comparative study between Gona and Ain Boucherit Oldowan assemblages that will be available in a forthcoming publication. 


\begin{tabular}{|c|c|c|c|c|c|c|}
\hline \multicolumn{7}{|c|}{$\mathrm{Al}$ centre } \\
\hline Sample & $\begin{array}{l}\text { Number of } \\
\text { repeated } \\
\text { measurements }\end{array}$ & $\begin{array}{l}\text { Bleaching } \\
\text { coefficient } \\
(\%)\end{array}$ & $\begin{array}{l}\text { Measurement } \\
\text { repeatability } \\
(\%)\end{array}$ & $\begin{array}{l}D_{E} \\
\text { repeatability } \\
(\%)\end{array}$ & $\underset{\mathrm{r}^{2}}{\operatorname{Adj}}$ & $\begin{array}{c}\text { EXPLIN } \\
D_{\mathrm{E}} \\
(\mathrm{Gy})\end{array}$ \\
\hline AB1104 & 4 & $62.1 \pm 0.7$ & 3.2 & 10.4 & 0.997 & $2282+169$ \\
\hline \multicolumn{7}{|c|}{ Ti-Li centre (option D) } \\
\hline Sample & $\begin{array}{l}\text { Number of } \\
\text { repeated } \\
\text { measurements }\end{array}$ & \multicolumn{2}{|c|}{$\begin{array}{l}\text { Measurement repeatability } \\
(\%)\end{array}$} & $\begin{array}{l}D_{E} \\
\text { repeatability } \\
(\%)\end{array}$ & $\underset{r^{2}}{\operatorname{Adj}}$ & $\begin{array}{c}\text { EXPLIN } \\
D_{\mathrm{E}} \\
(\mathrm{Gy})\end{array}$ \\
\hline AB1104 & 3 & \multicolumn{2}{|l|}{2.2} & 12.3 & 0.997 & $2418+129$ \\
\hline
\end{tabular}

Table S1. Fitting results derived from the measurement of the $\mathrm{Al}$ and $\mathrm{Ti}$ (option D) centres in sample AB1104. The bleaching coefficient is expressed as the relative difference between the ESR intensities of the natural and bleached aliquots. Measurement repeatability is the overall variability (1 standard deviation) of the ESR intensities obtained for each aliquot over the repeated measurements. De repeatability is the variability (1 standard deviation) of the De results over the repeated measurements. 


\begin{tabular}{|l|l|l|l|l|l|l|l|}
\hline Sample & \multicolumn{4}{|l|}{ ICP measurements } & \multicolumn{4}{l|}{ High Resolution Gamma Spectrometry } \\
& $\begin{array}{l}\mathrm{U}-238 \\
(\mathrm{~Bq} / \mathrm{kg})\end{array}$ & $\begin{array}{l}\text { Th-232 } \\
(\mathrm{Bq} / \mathrm{kg})\end{array}$ & $\begin{array}{l}\mathrm{K}-40 \\
(\mathrm{~Bq} / \mathrm{kg})\end{array}$ & $\begin{array}{l}\mathrm{U}-238 \\
(\mathrm{~Bq} / \mathrm{kg})\end{array}$ & $\begin{array}{l}\mathrm{Rn}-222 \\
(\mathrm{~Bq} / \mathrm{kg})\end{array}$ & $\begin{array}{l}\text { Th-232 } \\
(\mathrm{Bq} / \mathrm{kg})\end{array}$ & $\begin{array}{l}\mathrm{K}-40 \\
(\mathrm{~Bq} / \mathrm{kg})\end{array}$ \\
\hline AB1104 & $31.71 \pm 0.32$ & $24.02 \pm 0.24$ & $0.55 \pm 0.01$ & $34.41 \pm 3.07$ & $31.38 \pm 2.00$ & $25.67 \pm 1.57$ & $0.56 \pm 0.02$ \\
\hline
\end{tabular}

Table S2. Comparison of the radionuclide contents obtained by ICP and HRGS analyses. 


\begin{tabular}{|c|c|c|c|c|c|c|c|c|c|}
\hline & $\begin{array}{c}\text { Measured water } \\
\text { content }(\%)\end{array}$ & \multicolumn{4}{|c|}{$\begin{array}{c}\text { Gamma dose rate } \\
(\mu \mathrm{Gy} / \mathrm{a})\end{array}$} & \multicolumn{4}{|c|}{ Ratios } \\
\hline & & 1 & 2 & 3 & 4 & $2 / 1$ & $3 / 1$ & $4 / 1$ & $4 / 2$ \\
\hline & & In situ & Laboratory & Laboratory & Laboratory & & & & \\
\hline Method & & Threshold & $\begin{array}{l}\text { ICP } \\
\text { Full } \\
\text { series }^{(1)} \\
\end{array}$ & $\begin{array}{l}\text { HRGS } \\
\text { Pre-Rn (2) }\end{array}$ & $\begin{array}{l}\text { HRGS } \\
\text { Full } \\
\text { series }^{(1)} \\
\end{array}$ & & & & \\
\hline AB1104 & 5.6 & $560 \pm 33$ & $651 \pm 11$ & $669 \pm 81$ & $692 \pm 78$ & 1.16 & 1.19 & 1.24 & 1.03 \\
\hline
\end{tabular}

Table S3. Comparison of the gamma dose rates derived from in situ and laboratory analyses. ${ }^{(1)}$ Gamma dose rate calculated using the full-series dose rate conversion factors from (38) (i.e. assuming equilibrium in the U-238 decay chain) and attenuated by the measured water content. (2) Calculation performed assuming that a constant disequilibrium has prevailed over time within the U-238 series (pre-Rn dose rate conversion factors from [38]) and attenuated by the measured water content. 


\begin{tabular}{|c|c|}
\hline Sample & AB1104 \\
\hline Internal dose rate $(\mu \mathrm{Gy} / \mathrm{a})$ & $50 \pm 30$ \\
\hline Alpha dose rate $(\mu \mathrm{Gy} / \mathrm{a})$ & $36 \pm 30$ \\
\hline Beta dose rate $(\mu \mathrm{Gy} / \mathrm{a})$ & $655 \pm 52$ \\
\hline Gamma dose rate $(\mu \mathrm{Gy} / \mathrm{a})$ & $467 \pm 430$ \\
\hline Cosmic dose rate $(\mu \mathrm{Gy} / \mathrm{a})$ & $27 \pm 10$ \\
\hline Total dose rate $(\mu \mathrm{Gy} / \mathrm{a})$ & $12 \overline{3} 5 \pm 101$ \\
\hline $\mathrm{D}_{\mathrm{E}}(\mathrm{Gy}) \mathrm{Al}$ centre & $2282 \pm 169$ \\
\hline $\mathrm{D}_{\mathrm{E}}(\mathrm{Gy})$ Ti-Li centre option D & $2418 \pm 129$ \\
\hline Weighted mean $D_{E}(G y)$ & $2368+103$ \\
\hline Age (ka) Al centre & $1848 \pm 171$ \\
\hline Age (ka) Ti-Li centre & $1969 \pm 193$ \\
\hline Combined Al-Ti age (ka) & $1917+177$ \\
\hline
\end{tabular}

Table S4. ESR age estimates obtained for sample AB1104. 


\begin{tabular}{l|l|l|l|l|l|l|l}
\hline NISP $(\mathbf{N M E})$ & $\begin{array}{l}\text { Very Large } \\
\text { NMI=2 }\end{array}$ & $\begin{array}{l}\text { Large } \\
\text { NMI=3 }\end{array}$ & $\begin{array}{l}\text { Medium } \\
\text { NMI=5 }\end{array}$ & $\begin{array}{l}\text { Small } \\
\text { NMI=3 }\end{array}$ & $\begin{array}{l}\text { Very Small } \\
\text { NMI=4 }\end{array}$ & Indeterminate & Total \\
\hline Skull & & & & $2(1)$ & $5(3)$ & $3(-)$ & $10(4)$ \\
\hline Horn & & & $3(1)$ & $2(1)$ & $15(5)$ & $1(-)$ & $21(7)$ \\
\hline Mandible & & & & $5(3)$ & & $5(3)$ \\
\hline Isolatedteeth & $2(-)$ & $5(-)$ & $9(-)$ & $6(-)$ & $15(-)$ & $1(-)$ & $38(-)$ \\
\hline Vertebrae & & $2(2)$ & $4(4)$ & $1(1)$ & $10(10)$ & $1(-)$ & $18(17)$ \\
\hline Rib & $1(1)$ & $3(1)$ & $2(1)$ & $4(2)$ & $4(1)$ & & $14(6)$ \\
\hline Scapula & & & $2(1)$ & & $5(3)$ & & $7(4)$ \\
\hline Humerus & & & $2(2)$ & $1(1)$ & $8(6)$ & & $11(9)$ \\
\hline Radius & & & $3(2)$ & & $14(7)$ & & $17(9)$ \\
\hline Ulna & & & & & $3(2)$ & & $3(2)$ \\
\hline Carpal & & & & & $1(1)$ & & $1(1)$ \\
\hline Coxa & & & & & $3(2)$ & $2(-)$ & $5(2)$ \\
\hline Femur & & & $1(1)$ & & $7(3)$ & & $8(4)$ \\
\hline Tibia & & $1(1)$ & $2(1)$ & $1(1)$ & $6(3)$ & & $10(6)$ \\
\hline Fibula & & & & & & & \\
\hline Tarsal & & $4(4)$ & $2(2)$ & $3(3)$ & $5(5)$ & & $14(14)$ \\
\hline Metapodial & & $1(1)$ & $4(2)$ & $2(2)$ & $29(16)$ & & $36(21)$ \\
\hline Phalanx & & & $4(4)$ & $2(2)$ & $9(9)$ & & $15(15)$ \\
\hline sesamoid & & & & $2(2)$ & & & $2(2)$ \\
\hline Long bone & & $1(-)$ & $5(-)$ & $3(-)$ & $2(-)$ & $4(-)$ & $15(-)$ \\
\hline Flat bone & & & & & & $9(-)$ & $9(-)$ \\
\hline Indeterminate & $2(-)$ & $\mathbf{5}(\mathbf{1})$ & & & & $\mathbf{2 9 6}(\mathbf{1 2 6})$ \\
\hline Total & & $\mathbf{4 4}(\mathbf{9 9 )}$ & $\mathbf{2 9}(\mathbf{1 6})$ & $\mathbf{1 4 6 ( 7 9 )}$ & $\mathbf{5 6}(-)$ & \\
\hline
\end{tabular}

Table S5. NISP, NME and NMI by mammal size groups in AB-Lw level of Ain Boucherit 


\begin{tabular}{|c|c|c|c|c|c|c|c|}
\hline NISP (NME) & $\begin{array}{l}\text { Very Large } \\
\text { NMI=2 }\end{array}$ & $\begin{array}{l}\text { Large } \\
\text { NMI=4 }\end{array}$ & $\begin{array}{l}\text { Medium } \\
\text { NMI=2 }\end{array}$ & $\begin{array}{l}\text { Small } \\
\text { NMI=1 }\end{array}$ & $\begin{array}{l}\text { Very Small } \\
\text { NMI=5 }\end{array}$ & Indeterminate & $\begin{array}{l}\text { Total } \\
\text { NMI }=14 \\
\end{array}$ \\
\hline Skull & & $1(1)$ & $2(2)$ & & $8(6)$ & $1(-)$ & $12(9)$ \\
\hline Horn & & & $1(-)$ & & $13(-)$ & & $14(-)$ \\
\hline Mandible & & $1(1)$ & $1(1)$ & & $3(3)$ & & $5(5)$ \\
\hline Isolatedteeth & $1(-)$ & $16(-)$ & $15(-)$ & $1(-)$ & $9(-)$ & $2(-)$ & $44(-)$ \\
\hline Vertebrae & $1(1)$ & & $1(1)$ & & $1(1)$ & & $3(3)$ \\
\hline Rib & $1(1)$ & $4(2)$ & $4(1)$ & & $2(1)$ & & $11(5)$ \\
\hline Scapula & $1(1)$ & & & & & & $1(1)$ \\
\hline Humerus & & & $1(1)$ & & $3(2)$ & & $4(3)$ \\
\hline Radius & & $1(1)$ & $1(1)$ & & $2(1)$ & & $4(3)$ \\
\hline Ulna & & & & & $1(1)$ & & $1(1)$ \\
\hline Carpal & & $1(1)$ & & & $1(1)$ & & $2(2)$ \\
\hline Coxa & & & & & $1(1)$ & & $1(1)$ \\
\hline Femur & & $1(1)$ & $1(1)$ & & $1(1)$ & & $3(3)$ \\
\hline Tibia & & $8(8)$ & $1(1)$ & & $5(2)$ & & $14(11)$ \\
\hline Fibula & & & & & $1(1)$ & & $1(1)$ \\
\hline Tarsal & & $2(2)$ & $1(1)$ & & $1(1)$ & & $4(4)$ \\
\hline Metapodial & & $4(4)$ & $1(1)$ & & $9(6)$ & & $14(11)$ \\
\hline Phalanx & & $1(1)$ & & $1(1)$ & $6(6)$ & & $8(8)$ \\
\hline Long bone & & $14(-)$ & $49(-)$ & & $31(-)$ & & $94(-)$ \\
\hline Flat bone & $1(-)$ & & $7(-)$ & & $1(-)$ & & $9(-)$ \\
\hline Indeterminate & $3(-)$ & $5(-)$ & $4(-)$ & & $2(-)$ & $14(-)$ & $28(-)$ \\
\hline Total & $8(3)$ & $59(22)$ & $90(11)$ & $2(1)$ & $101(34)$ & $17(-)$ & $277(71)$ \\
\hline
\end{tabular}

Table S6. NISP, NME and NMI by mammal size groups in AB-Up of Ain Boucherit. 


\begin{tabular}{|c|c|c|c|c|c|c|}
\hline AB-Lw & $\begin{array}{c}\text { Very } \\
\text { Large Size }\end{array}$ & $\begin{array}{l}\text { Large } \\
\text { Size }\end{array}$ & $\begin{array}{c}\text { Medium } \\
\text { Size }\end{array}$ & $\begin{array}{c}\text { Small } \\
\text { Size }\end{array}$ & $\begin{array}{c}\text { Very } \\
\text { Small Size }\end{array}$ & Indeterminate \\
\hline Mandible (1) & & & & & $\begin{array}{c}1 \text { (D) } \\
\text { body, buccal } \\
\text { side }\end{array}$ & \\
\hline Molar (1) & & $\begin{array}{c}1(\mathrm{D}) \\
\text { buccal side }\end{array}$ & & & & \\
\hline $\operatorname{Rib}(4)$ & $\begin{array}{c}1(\mathrm{E}) \\
\text { shaft, ventral } \\
\text { side }\end{array}$ & $\begin{array}{c}2(\mathrm{E}, \mathrm{D}) \\
\text { shaft, ventral and } \\
\text { dorsal side }\end{array}$ & & $\begin{array}{c}1(\mathrm{D}) \\
\text { shaft, dorsal } \\
\text { side }\end{array}$ & & \\
\hline Humerus (2) & & & $\begin{array}{c}1(\mathrm{D}) \\
\text { distal shaft, } \\
\text { posterior side }\end{array}$ & & $\begin{array}{c}1(\mathrm{D}) \\
\text { distal shaft, } \\
\text { anterior side }\end{array}$ & \\
\hline Radius (2) & & & & & $\begin{array}{c}2(\mathrm{D}) \\
\text { medial shaft, } \\
\text { posterior and } \\
\text { lateral side }\end{array}$ & \\
\hline Femur (1) & & & $\begin{array}{c}1(\mathrm{M}) \\
\text { shaft, lateral } \\
\text { side }\end{array}$ & & & \\
\hline Tibia (2) & & & & $\begin{array}{c}1(\mathrm{D}) \\
\text { distal shaft, } \\
\text { posterior side }\end{array}$ & $\begin{array}{c}1(\mathrm{D}) \\
\text { distal shaft, } \\
\text { anterior side }\end{array}$ & \\
\hline Metacarpal (2) & & & & $\begin{array}{c}1(\mathrm{~S}) \\
\text { shaft, } \\
\text { anterior side }\end{array}$ & $\begin{array}{c}1(\mathrm{~S}) \\
\text { shaft, } \\
\text { anterior side }\end{array}$ & \\
\hline Calcaneus (1) & & $\begin{array}{c}1(\mathrm{~S}) \\
\text { lateral side }\end{array}$ & & & & \\
\hline Long bone (5) & & & $\begin{array}{c}2(\mathrm{D}, \mathrm{M}) \\
\text { shaft }\end{array}$ & & & $\begin{array}{l}\text { (D) } \\
\text { shaft }\end{array}$ \\
\hline Total AB-Lw (21) & 1 & 4 & 4 & 3 & 6 & 3 \\
\hline AB-Up & $\begin{array}{c}\text { Very } \\
\text { Large Size }\end{array}$ & $\begin{array}{l}\text { Large } \\
\text { Size }\end{array}$ & $\begin{array}{c}\text { Medium } \\
\text { Size }\end{array}$ & $\begin{array}{c}\text { Small } \\
\text { Size }\end{array}$ & $\begin{array}{c}\text { Very } \\
\text { Small Size }\end{array}$ & Indeterminate \\
\hline Femur (1) & & & $\begin{array}{c}1(\mathrm{M}) \\
\text { shaft, } \\
\text { posterior side }\end{array}$ & & & \\
\hline Tibia (4) & & $\begin{array}{c}3(\mathrm{D}, \mathrm{M}) \\
\text { shaft, anterior } \\
\text { and posterior side }\end{array}$ & & & $\begin{array}{c}1(\mathrm{M}) \\
\text { shaft, lateral } \\
\text { side }\end{array}$ & \\
\hline Long bone (4) & & & $\begin{array}{c}4(\mathrm{D}, \mathrm{M}) \\
\text { shaft }\end{array}$ & & & \\
\hline Total AB-Up (9) & - & 3 & 5 & - & 1 & - \\
\hline
\end{tabular}

Table S7. NISP with cutmarks and percussion marks in AB-Lw and AB-Up by animal size groups and skeletal elements (location in italic). $\mathrm{S}=$ Skinning; E=Evisceration; $\mathrm{D}=$ Defleshing; $\mathrm{M}=$ Marrow extraction. 


\begin{tabular}{|c|c|c|c|c|}
\hline Taxa & $\begin{array}{c}\text { Ain Boucherit AB-Lw } \\
\text { (Mb P) }\end{array}$ & $\begin{array}{c}\text { Ain Boucherit AB-Up } \\
(\text { Mb R) }\end{array}$ & El Kherba & Ain Hanech \\
\hline Ostracoda indet. & $\mathrm{x}$ & & & \\
\hline Gasteropoda indet. & $\mathrm{x}$ & & $\mathrm{x}$ & \\
\hline Teleostei indet. & $\mathrm{x}$ & & & \\
\hline Mauremys leprosa & $\mathrm{x}$ & & $\mathrm{x}$ & \\
\hline Crocodylia indet. & $\mathrm{x}$ & & $\mathrm{x}$ & \\
\hline Struthio barbarus & $\mathrm{x}$ & & & \\
\hline Vulpes sp. & $\mathrm{x}$ & $\mathbf{x}$ & & \\
\hline Canis primaevus & $\mathrm{X}$ & & $\mathrm{x}$ & \\
\hline Canis cf. falconeri & & & & $\mathrm{x}$ \\
\hline Ursus sp. & & $\mathrm{x}$ & & \\
\hline cf. Pliocrocuta perrieri & $\mathrm{x}$ & & & \\
\hline Crocuta crocuta & & & $x$ & $\mathrm{x}$ \\
\hline Panthera sp. & & & $\mathrm{x}$ & \\
\hline Felis? & & & $\mathrm{x}$ & \\
\hline Lagomorpha & $\mathrm{x}$ & & $\mathrm{x}$ & \\
\hline Muroidea indet. & $\mathrm{x}$ & & & \\
\hline Anancus osiris & $\mathrm{x}$ & & & sp. \\
\hline Mammuthus africanavus & $\mathrm{x}$ & $?$ & & \\
\hline $\begin{array}{l}\text { Elephas recki ileretensis / } \\
\text { Mammuthus meridionalis I } \\
\text { "Elephas moghrebiensis" }\end{array}$ & & & $\mathrm{x}$ & $\mathrm{x}$ \\
\hline Ceratotherium mauritanicum & $\mathrm{x}$ & & $\mathrm{x}$ & $\mathrm{x}$ \\
\hline "Dicerorhinus" africanus & & & $?$ & $?$ \\
\hline Hipparion libycum & $\mathrm{x}$ & & & $\mathrm{x}$ \\
\hline Equus numidicus & $\mathrm{x}$ & cf. & & \\
\hline Equus tabeti & & & $\mathrm{x}$ & $\mathrm{x}$ \\
\hline Equus aff. oldowayensis & & & $\mathrm{X}$ & $\mathrm{x}$ \\
\hline Hippopotamus sp. & $\mathrm{x}$ & $\mathrm{x}$ & & \\
\hline Hippopotamus gorgops & & & $\mathrm{x}$ & $\mathrm{x}$ \\
\hline Suidae indet. & $\mathrm{X}$ & $\mathrm{x}$ & & \\
\hline Kolpochoerus heseloni & & cf. & $\mathrm{x}$ & $\mathrm{x}$ \\
\hline "Giraffa" pomeli & $\mathrm{x}$ & $?$ & $\mathrm{x}$ & $\mathrm{x}$ \\
\hline
\end{tabular}




\begin{tabular}{|c|c|c|c|c|}
\hline Sivatherium maurusium & $\mathrm{X}$ & & $\mathrm{X}$ & $\mathrm{X}$ \\
\hline Taurotragus gaudryi & & $?$ & & \\
\hline Pelorovis (?) & $\mathrm{X}$ & $?$ & $\mathrm{X}$ & \\
\hline "Bos bubaloides" & & & & $\mathrm{X}$ \\
\hline Gazella setifiensis & $\mathrm{X}$ & cf. & & \\
\hline Gazella pomeli & & & $\mathrm{X}$ & $\mathrm{X}$ \\
\hline Oryx eleulmensis & & & & $\mathrm{X}$ \\
\hline Parantidorcas latifrons & $\mathrm{X}$ & $\mathrm{X}$ & & \\
\hline $\begin{array}{l}\text { Parmularius? eulmensis / } \\
\text { Parmularius altidens }\end{array}$ & $\mathrm{X}$ & cf. & & \\
\hline $\begin{array}{l}\text { Damaliscus cuiculi / } \\
\text { Parmularius braini }\end{array}$ & $\mathrm{X}$ & & & \\
\hline Numidocapra crassicornis & & & $\mathrm{X}$ & $\mathrm{X}$ \\
\hline Connochaetes tournoueri & $\mathrm{X}$ & $\mathrm{X}$ & & \\
\hline Alcelaphini? & & & & $\mathrm{X}$ \\
\hline
\end{tabular}

Table S8. Faunal lists of the Ain Boucherit and the nearby Ain Hanech and El Kherba sites. The list of the Ain Boucherit Mb R fauna is new, whereas for the other localities updated after (63) and (64). 


\begin{tabular}{|l|l|l|}
\hline Sites & Collections & References \\
\hline Ain Jourdel & Muséum naional d'Histoire naturelle, Paris & \\
\hline Shungura Fm & & 65,66 \\
\hline Ain Boucherit & Muséum naional d'Histoire naturelle, Paris & \\
\hline Koobi Fora Fm & & 62 \\
\hline Olduvai Beds 1 \& 2 & $\begin{array}{l}\text { Naturalis Biodiversity Center, Leiden, } \\
\text { Natural History Museum, London }\end{array}$ & 67 \\
\hline El Kherba & Bardo Museum, Algiers & \\
\hline Ain Hanech & $\begin{array}{l}\text { Muséum naional d'Histoire naturelle, Paris, } \\
\text { Bardo Museum, Algiers }\end{array}$ & \\
\hline Tighennif & & 68 \\
\hline Daka & & 69 \\
\hline Zwartklip, Equus Cave & & 70 \\
\hline Sidi Bou Knadel, Guyotville & Muséum naional d'Histoire naturelle, Paris & \\
\hline Recent species & & 68 \\
\hline
\end{tabular}

Table S9. Data sources on Equus 


\begin{tabular}{|l|lc|lc|}
\hline \multicolumn{1}{|c|}{ Artefact categories } & \multicolumn{2}{|c|}{ AB-Lw } & \multicolumn{2}{|c|}{ AB-Up } \\
\hline Cores \& core forms* & $\mathrm{N}$ & $\%$ & $\mathrm{~N}$ & $\%$ \\
Unifacial choppers & 3 & 17.64 & 40 & 16.94 \\
Bifacial choppers & 1 & 5.88 & 19 & 8.05 \\
Polyhedron/cores & 2 & 11.76 & 55 & 23.30 \\
Subspheroids & 1 & 5.88 & 4 & 1.69 \\
Spheroids & - & - & 2 & 0.84 \\
Split cobbles & - & - & 1 & 0.42 \\
Sub-Total cores \& core forms & 7 & 41.17 & 121 & 14.5 \\
\hline Whole flakes & 9 & 52.94 & 65 & 7.79 \\
\hline Retouched pieces & 1 & 5.88 & 3 & 0.35 \\
\hline Fragments & - & - & 47 & 5.63 \\
\hline Sub-Total assemblage & 17 & 100 & 236 & 28.29 \\
\hline Elements $<2 \mathrm{~cm}$ & $\mathrm{NA}$ & $\mathrm{NA}$ & 603 & 72.3 \\
\hline Total & 17 & 100 & 834 & 100 \\
\hline
\end{tabular}

Table S10. Overall presentation of lithic assemblages of Ain Boucherit lower archaeological level (AB-Lw) and upper archaeological level (AB-Up). * Note that frequencies of types within the cores and core forms category are calculated relative to the total of the assemblages $>2 \mathrm{~cm}$ of maximum dimension (17 and 236, respectively). 